

\section{HARVARD UNIVERSITY.}

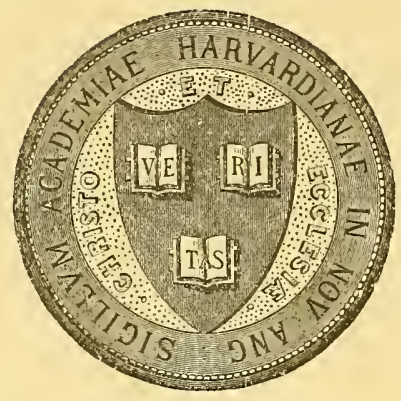

LIBRARY

OF THE

MUSEUM OF COMPARATIVE ZOÖLOGY. 39,856

GIFT OF

ALEXANDER AGASSIZ.

Entered fune 27,1913 
ah Ajaseir 





\section{Untersuchungen}

über

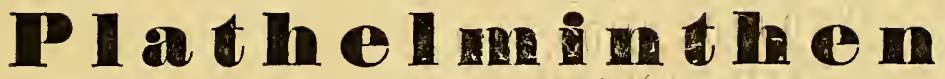

von

\section{Anton Schneidér,}

Professor der Zoologie und vergleichenden Anatomie an der Universität Giefsen.

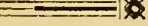

|

\section{Giefsen, 1873.}

J. Ricker'sche Buchhandlung. 
(Separatabdruck aus dem 14. Jahresbericht der oberhessischen Gesellschaft für Natur- und Heilkunde). 
Herrn

\title{
Rudolf Leuckant
}

\author{
gewidmet.
}



Vorliegende Untersuchungen wurden zunächst an Mesostomum Ehrenbergii begonnen, welches sich wegen seiner Gröfse, Durchsichtigkeit und Lebenszähigkeit zu den verschiedensten Versuchen vorzüglich eignet. $\mathrm{Da}$ wir diefs Thier aus den Arbeiten von Focke, O. Schmidt und Leuckart bereits genau kennen, so war eine Schilderung scines gesammten Baues unnöthig, ich konnte mich aut die bisher weniger berücksichtigten Punkte beschränken. Allmählich haben sich aber meine Untersuchungen über die gesammte Klasse der Plathelminthen ausgebreitet. Sie betreffen vorziiglich die Muskeln, die Drüsen, das Nervensystem, die Systematik der Plathelminthen im Allgemeinen und die Physiologie der Befruchtung und den Zelltheilungsprocef's bei Mesostomum Ehrenbergii.

\section{Epithel.}

Nicht alle Plathelminthen besitzen ein Epithel, es fehlt den Cestoden und Trematoden. Man könnte vielleicht annehmen, dafs die feste Cuticula, welche ihren Körper bedeckt, abgesondert sei von einein darunter liegenden Epithel. Allein die Muskeln liegen dieser Haut so fest an, dafs ich diese Cuticula eher mit der Basementmembran, welche bei den Epithel tragenden Plathelminthen zwischen der Muscularis und der Epithelschicht liegt, vergleichen möchte.

Von den Polystomiden wissen wir durch die Untersuchungen von $\mathrm{Zeller}{ }^{*}$ ) und Willmoes-Suhm **), dafs sie

*) I, S. 172.

**) II, S. 33 . 
zuerst ein Wimperepithel besitzen, welches verloren geht. Auch die Distomidenembryonen verlieren, wie bekannt, entweder das Wimperepithel bald nach dem Verlassen des Ei's, oder vielleicht schon vorher. Wie sich aber die Cercarien verhalten, ist unbekannt. Unter den Cestoden kennen wir ein Wimperepithel nur bei den Embryonen von Bothriocephalus, Ligula und Triaenophorus. Dafs die Zellschicht, welche bei den Hirudineen unter der Cuticula liegt, ein Epithel ist, halte ich für zweifelhaft. Aus den Schilderungen Leydig's*) geht schon hervor, dafs es eine eigenthümliche Structur hat.

Nach den Untersuchungen von M. S chulze**) soll das Epithel der Turbellarien aus verschmolzenen Zellen bestehen, deren Kerne untergegangen sind. Icl habe selbst von lebenden Plathelminthen genauer nur die Haut der Mesostomeen, namentlich von M. Ehrenbergii untersucht. Sie besteht aus deutlich grofsen polyedrischen Zellen (Taf. V, 1) von einer ziemlichen Dicke, welche je in ihrer Mitte einen nach innen vorspringenden Kern besitzen. Derselbe ist vielfach ausgebuchtet und mit mehreren Kernkörpern versehen. Die Wimpern der Zellen stehen im Allgemeinen ziemlich dünn, nur in der Mitte der Bauchseite ist ein dichter Wimperpelz. Eine Theilung der Zellen habe ich am ausgewachsenen Thier nicht finden können. Setzt man Essigsäure zu, so lösen sich die Zellen einzeln $a b$ und es tritt eine merkwürdige Eigenschaft an ihnen hervor; sie scheinen plötzlich wie aus kleinen Polyedern zusammengesetzt, ähnlich Bienenwaben, als ob die Wände der $\mathrm{W}$ aben aus fester Substanz beständen, während der übrige Theil flüssig ist. An der lebenden Zelle am unverletzten Thier ist von dieser Structur nichts zu bemerken. Vielmehr sieht man dann in den Zellen mit einiger Regelmälsigkeit runde oder elliptische helle Körper liegen. Hat man das Thier unter wenig Wasser kurze Zeit auf dem Objectglas liegen lassen, so sieht man diese Körper einzeln oder in grölserer

*) III, S. 104.

**) IV, S. 8. 
Menge freiliegen (Taf. III, 5c). Sie quellen in Wasser langsam auf und lösen sich in Säuren. Es sind jene Waben offen. bar so entstanden dafs die Körper aufgelöst werden und die übrig bleibende Zellsubstanz - die ja den geringeren Theil bildet - gegen die flüssigen Hohlräume als polyedrische Gränze absticht. Der Anblick ist so überraschend, dafs Leuckart*) geglaubt hat, das Epithel bestände aus kleinen kernlosen Zellen. Die Zellsubstanz wird durch die Säure nicht gelöst, man kann die äufsere und innere Wand noch deutlich erkennen.

Wie die Haut der Mesostomeen bekommt auch die Haut der Süfswasser-Planarien nach Einwirkung von Essigsäure das wabenartige Ansehen. Hier rührt sie von der Auflösung eines andern in der Haut liegenden Gebildes her, nämlich der Stäbchen, welche wir später besprechen werden; die wahren Zellgrenze der Planarien habe ich nicht gefunden. Bei Polia besteht das Epithel aus sehr dünnen cylindrischen oder vielmehr keilförmigen Zellen, die ihre Spitzen theils nach oben, theils nach unten richten, wie diefs so häufig vorkommt. Auch die Kerne sind aufserordentlich klein. Die Abbildung Taf. III, 3 ist etwas schematisch ausgefallen. Aehnliche Zellen scheinen bei Nemertes und Planaria vorhanden zu sein. Das Epithel ist vielfach durchbohrt für den Austritt der Stäbchen und Drüsen. Eine Basilarmembran des Epithels, wie sie $Q$ uatrefages und nach ihm Keferstein bei den Planarien annimmt, ist zwar da, ich möchte sie aber eher als die äufserste Gränzschicht der Muscularis bezeichnen, da dieselbe mit der Ringmuskulatur untrennbar verwachsen ist. Weiter unten bei Besprechung der Muskeln wird dieselbe eingehender behandelt werden.

\section{Das mittlere Blatt.}

Unter dem mittleren Blatt begreifen wir alles was zwischen Epithel und Darmkanal gelegen ist. Da das Epithel, ja sogar Epithel und Darmkanal mitunter fehlen, so kann ein solches Thier aus zwei oder nur einem Blatt bestehen.

*) V, S. 236 . 
Der Charaeter, welchen man für das mittlere Blatt der Wirbelthiere annimmt, fehlt dieser Schicht der Plathelminthen aber vollständig. Insbesondere ist es reich mit Drüsen versehen. Aufserdem enthält es das Muskel-, Nerven-, Blutund Wassergefälssystem, die Geschlechtsorgane, BindegewebsFett- und Pigmentzellen. Bei einem grofsen Theil der Plathelminthen hängt bekanntlich alles diel's so innig zusammen, dafs man die einzelnen Theile nicht präpariren kann, und aus diesem Grund mufs man die Untersuchung vorzugsweise an Schnitten anstellen, die am besten in der jetzt so verbreiteten Weise mit Carmin gefärbt, in Nelkenöl autgehellt und in Canadabalsam auf bewahrt wurden.

\section{Muskeln.}

Ehe wir die Histologie der Muskeln betrachten, wollen wir zunächst die Anordnung, Schichtung und Richtung der Muskelfasern darstellen. Dabei müssen wir aut die Systematik nothwendig Rücksicht nehmen. Wie schon an einem anderen Orte nachgewiesen wurde *), können wir zwei Gruppen der Plathelminthen unterscheiden, die sich nach der Entwickelungsgeschichte als die Stamm- und Generationsform bezeichnen lassen. In der Stammform liegt zu äufserst eine Schicht Ringfasern. Darauf folgen zwei Schichten, in deren jeder die Fasern parallel liegen, aber so, dafs die Richtungen beider Schichten sich unter einem Winkel schneiden, welcher von der Längsaxe halbirt wird. Man kann sie als Diagonalschicht betrachten, aber auch als eine Schraubenschicht. Bei Hirudo medicinalis liefs sich feststellen, dal's die äufsere Schicht, wenn man sich der Bezeichnung wie bei Schneckenschaalen bedient-links gewunden ist. Nach Innen von dieser Schicht kommt eine Schicht Längsfasern. Von der Rückenzur Bauchseite laufen Sagittalfasern, welche zwischen der Ringschicht mit vielen Ausläufern wurzeln. Diese Sagittalfasern hindern den Darmkanal in seiner freien Entfaltung und zwingen ihn zu den hufeisenförmigen und dendritischen Ver-

*) XXVIII. 
ästelungen, die unter den Trematoden und Planarien so häufig vorkommen. Bei den segmentirten Gruppen der Stammform, zu welchen wir die $e_{i}^{5}$ Hirudineen, Onychophoren und Poliadeen rechnen, beschränken sich die Sagittalfasern mehr auf die Seitentheile, so dals der Darmkanal gestreckt verlaufen kann.

Es wird auffallen, dal's wir die Poliadeen (Polia uud Borlasia) mit den Hirudineen und Onychophoren zusammenstellen. Jedenfalls, wenn man auch ihre Segmentirung, worüber wir weiter unten beim Nervensystem sprechen, bestreiten will, sind aber sicher ihre Muskeln ganz wie bei der Stammform angeordnet. Sie unterscheiden sich dadurch von den Nemertes, mit denen man sie bisher fälschlich zusammengestellt hat. Wir werden zeigen, dafs aber auch in vielen anderen Beziehungen zwischen den Poliadeen und Nemertes ein grolser Unterschied besteht.

Die Generationsform zeigt folgende Anordnung der Muskeln. Zu äufserst trifft man bei allen ohne Ausnahme eine dünne Schicht äufserer Querfasern, darauf eine eben so dünne Schicht Längsfasern, welche nahe bei einander liegen. Man kann sie als die rechtwinklich gekreuzte oder Hautmuskelschicht bezeichnen. Diese Schicht ist bei den Rhabdocölen bereits von M. Schulze, bei den Cestoden von Stieda beschrieben, ich habe sie noch bei Nemertes und Bipalium nachweisen können. Dann folgt eine Schicht Längsfasern, welche meist durch eine breite Parenchymzone von der Hautmuskelschicht getrennt ist und sich immer durch eine grölsere Dicke ihrer Elemente auszeichnet. Diese zweite Schicht ist an den Gliedern von 'Tetrarhynchus nur durch einen schmalen, in der dorsalen und ventralen Linie verlaufenden Streifen vertreten. Darauf folgt eine Ringschicht und darauf können wieder wie bei Nemertes Längsfasern folgen (Taf. VI, Fig. 1 und 2).

Sagittalfasern sind immer vorhanden, welche sich wie in der Stammform wurzelartig in der äufsersten Schicht befestigen. Sie beschränken sich, wenn ein Darmkanal vorhanden ist, 
auf die Seitentheile, während sie bei den Cestoden durch die ganze Breite des Thieres gehen.

Taf. III, Fig. 2. ist die Muskulatur von Mesostomum Ehrenbergii in der dorsalen Ansicht abgebildet, mit Hinweglassung der gleichmäfsig über das ganze Thier ausgebreiteten, rechtwinklich gekreuzten äufsersten Schichten. Auf den ersten Blick wird man in der Figur die oben gegebene Beschreibung der Muskulatur kaum wieder erkennen und doch zeigt sie alle typischen Fasern. Die Punkte in den Seitentheilen sind die Sagittalfasern, die Ringfasern wird man leicht erkennen, die Längsfasern fehlen in der Gegend des Mundes, sind aber im Rücken und Kopftheil vorhanden, nur etwas gegen die Längsaxe geneigt.

Auch hier wird man sich wundern, dafs Bipalium (Sphyrocephalus Schmarda), welches man bisher durch die Lebensweise verführt für eine Landplanarie hielt, zu der Generationsform in der Nähe der Rhabdocölen gestellt wird. Diefs Beispiel zeigt von neuęm, welches mächtige Hülfsmittel für die Erkennung der Verwandschaft die Muskulatur gewährt. Ein Blick auf den Querschnitt zeigt die wahre Verwandschaft und den Unterschied von den Planarien (Taf. VII, Fig. 7).

Im Kopftheil der Cestoden und Nemertes tritt eine ganz neue Anordnung der Muskulatur auf, welche die verschiedenen Formen des Kopfes dieser Thiere bedingt. Ich benutze diese Gelegenheit, um darauf hinzuweisen, dafs so lange keine festen Theile vorhanden sind, die Muskulatur die ganze Gestalt eines Thieres bestimmt. — Eine Bemerkung für diejenigen, welche es noch für paradox halten, bei der Systematik die Muskulatur zu berücksichtigen. - Im Kopf dieser Thiere ordnen sich die Muskeln so an, dafs sie auf dem Querschnitt das Bild von Strahlenbüscheln geben. 
Denkt man sich vier Strahlenbüschel wie in nebenstehender Figur, so entsteht ein vierkantiger Kopf, wie bei Taenia und rückt ein Paar der Büschel weiter ab von dem andern, so entstehen zwei seitliche Gruben,

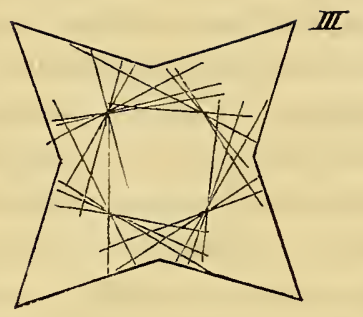
wie bei den Dibothrien und Nemertes. Bei den Tetrarhynchen und Tetrabothrien ist die Zahl der Strahlenbüschel eine gröfsere und wechselnde, dadurch werden die wunderbaren Formen ihrer Sauggruben bedingt, die wir aus den Werken von van B eneden und G. R. W a ge ner kennen.

Auch der ganze Körper eines Thieres kann die vierkantige Gestalt besitzen, z. B. Mesostomum tetragonum; sie wird wahrscheinlich durch eine ähnliche Disposition der Muskelfasern hervorgebracht.

Gehen wir nun zur Histologie des Muskelsystems über. Das Element, von welchem wir bei der Betrachtung derselben ausgehen, ist ein Säulchen fibrillärer Substanz. Es kann solid sein, z. B. bei Nemertes, Hirudo, Taenia, oder ein Röhrchen z. B. bei Ligula, Planaria, Bipalium. Diese Säulchen oder Fasern werden von anderen Schriftstellern, z. B. Stie d a $*$ ) und Sommer-Landois **), als Muskelzellen betrachtet. Bis jetzt wenigstens läfst sich kaum beweisen, dafs diese Säulchen Zellen sind. Einen Kern kann man in oder an ihnen eng anliegend niemals sehen. Ich wähle deshalb einen von ihrem Verhältnifs zur Zelle unabhängigen Ausdruck.

Die Anordnung dieser Säulchen zeigt zwei Modificationen, welche man als Stufen der Entwickelung des Muskelgewebes 
betrachten kann. Auf der tieferen Stufe sind sie einzeln in ein ziemlich festes Protoplasma eingebettet, auf der höheren Stufe liegen sie zu mehreren in einem von festerer Substanz umschlossenen Raum, welcher eine gerinnbare sehr flüssige Proteïnsubstauz enthält. In dem letzteren Zustand gleichen sie einem Primitivbündel. Zwischen beiden Stufen giebt es eine Mittelstufe, auf der auch ein einzelnes Säulchen in einem solchen mit Flüssigkeit gefüllten Raum steht. Dieser Fall ist mir nur einmal im Kopf von Tetrarhynchus vorgekommen.

Beide Stufen kommen sowohl in der Generations- wie der Stammform vor, es kann die ganze Muskulatur eines Thieres auf einer der beiden Stufen stehen, oder die Muskulatur ist gemischt, dann steht immer die Längsmuskulatur allein auf der höheren Stufe. Wir können also danach drei Gruppen von Plathelminthen unterscheiden, die aber, wie ich hervorheben will, weder mit der Körpergestalt noch mit der sonstigen Organisation zusammenfallen.

Die Cestoden bieten das klarste Bild der ersten Gruppe dar. Dort ist der ganze Körper von einem Protoplasma gebildet, in welchen aufser den Muskeln auch die Nerven, Wassergefiifse, Geschlechtsorgane eingebettet liegen. Dasselbe ist feinkörnig, löst sich in heifser Salpetersäure, es hängt mit den Säulchen zusammen, beim Zerreifsen bleiben immer Stücke davon an der Muskelfaser hängen. In diesem Protoplasma sind bei einigen, z. B. den Bothriocephalus und Tetrarhynchus, viele Kerne eingebettet, während bei Taenia die Kerne selbst am Hals, wo man doch eine Wucherung erwarten sollte, äufserst sparsam sind. Bei Ligula habe ich sie ganz vermilst, man findet sie gleichwohl in den Stellen eingeschlossen, welche die Anlage der Geschlechtsorgane enthalten. Dals die Kalkkörper aus der Verkalkung von Zellen oder Kernen hervorgehen, ist unbewiesen und durchaus unwahrscheinlich. Die erste Anlage der Kalkkörper bemerkt man als eine unverkalkte Körperstelle, welche in Karmin sich tief roth färbt. Sie besitzt bereits dic definitive GröIse, welclıe immer bedeutender ist als die der Kerne. Sommer und Lando is lassen den Körper des Bothriocephalus latus aus 
Zellen zusammengesetzt sein, einmal spindelförmige, welche eine Rindenschicht bilden und kugelförmige in der Mitte des Körpers. Dal's sich an der Rinde des Körpers durch Zupfen Spindeln mit Kernen isoliren lassen, ist gewifs, wenn man aber bedenkt, dafs diese Rindenschicht von einer Menge radialer Muskelfasern - die Ausstrahlung der Sagittalfasern - durchsetzt wird, so ist klar, warum sie sich leicht in längliche Stïcke wird spalten lassen. Was die runden Stellen in der Mitte des Körpers betrifft, so finden sie sich in der Halsgegend noch nicht. Weiter nach hinten sieht man in dem Protoplasma zuerst einzelne helle Räume auftreten, die sich an den reifen Gliedern stark vermehrt haben, so dafs das übrige Protoplasma nur dünne Wände zwischen ihnen bildet. Von Protoplasma sind die Räume sicher nicht erfüllt, sondern von Flüssigkeit. Wären sie Zellen, so mürste man folglich die Kerne an der Wand der Zelle sitzen sehen. Dies ist mir aber nie gelungen, die Kerne liegen vielmehr in der festen Substanz zwischen den Räumen. Mitunter scheint allerdings ein Kern in der Mitte der Zelle zu stehen, dann ist man aber nicht sicher, dafs er in einem darunterliegenden Stücke fester Substanz sich befindet. Auch bei Ligula finden sich solche helle Räume.

Bei den Cestoden geht dies Protoplasma in keine höhere Differenzirung ein. Es fehlen denselben namentlich die Drüsenzellen, welche bei den übrigen Plathelminthen einen grofsen Raum einnehmen, wenn nicht ganz, so doch fast ganz. Indefs liegt dies Protoplasma gewifs nicht als eine homogene Masse in dem Innern des Thieres. Wir haben eben nur wenig und sehr grobe Mittel, um die Organisation dieser Substanz zu untersuchen. Kocht man eine Ligula in Salpetersäure, so kann man den inneren Theil des Körpers, welcher keine Längsmuskeln enthält, in Platten zerlegen, die dadurch zusammenhängen, dal's der weiter unten zu beschreibende Nervenstrang durch sie hindurchgeht und mit ihnen verwachsen ist. Diese Platten bestehen ans einer feinkörnigen Substanz, in welcher die Quer-, Ring- und Sagittalfasern eingebettet liegen. Nach aufsen strahlen diese Platten 
zwischen den Maschen der Längsfasern nach aufsen. Man möchte danach annehmen, dafs das Protoplasma der in dem Querschnitt verlaufenden Fasern ein zusammenhängendes Ganze bildet und eben so das Protoplasma der in der Längsrichtung verlaufenden Fasern. Das Protoplasma der Längsfasern wird durch das Kochen in Salpetersäure leichter gelöst. Aus den Lücken, die zwischen den Querplatten entstehen, läfst sich vermuthen, dal's das Protoplasma der Längsschicht auch nach Innen zwischen die Querplatten dringt. Wie vorsichtig man sein muls, eine grolse verschmolzene Zellmasse da anzunehmen, wo keine Gränze der 'Cellen zu sehen ist, lehren die Untersuchungen Li e b e rk üh n's bei Spongien. Es gelang ihm scheinbar ganz homogene Zellmassen durch Erwärmen in ihre einzelnen Zellen zu zerlegen.

Unter den Trematoden stehen einige ebenfalls auf dieser niederen Stufe, so sind bei Distoma veliporum und hepaticum die Säulen der Längsmuskeln nicht in hellen Räumen eingeschlossen. Das Protoplasma. ist bei D. veliporum von einem aufserordentlich feinen Netz von Fasern und Membranen durchzogen, welches zwar viele runde Kerne enthält; doch erscheinen sie mir nicht zahlreich genug, als daf's man auf jede Masche des Netzes einen Kern rechnen könnte. Auch bei D. hepaticum scheint das Protoplasma auf derselben Stufe zu stehen. Leuckart*) und nach ihm Blumberg**) geben zwar an, dals zwischen den Muskeln grolse kernhaltige Zellen liegen und der erste Anblick eines Querschnitts spricht unleugbar dafür. Aber es scheint mir, dals ähnlich wie bei den Cestoden das Protoplasma von mit Flüssigkeit erfüllten Hohlräumen durchsetzt wird. An jüngeren Exemplaren von D. hepaticum ist das Protoplasma in der Nähe der Längsmuskeln ganz homogen und stellenweise auch in der Mitte. Tief zu stehen scheint mir auch die Gewebsbildung bei Octobothrium lanceolatum, ich will jedoch darïber nicht weiter sprechen, da meine Exemplare vielleicht nicht gut erhalten sind. 
Die Rhabdocölen und Bipalium haben Muskeln, welche durchweg auf der niederen Stufe bleiben, aber das Protoplasma ist nicht mehr so homogen wie bei den Cestoden. Soweit es zu den Muskeln gehört und ihnen sich anschmiegt ist es homogen. Sonst aber enthält es viele Drüsenzellen, und wie ich wenigstens von Mesostomum Ehrenbergii angeben kann, Zellen mit vielen Ausläufern, welche ein gelb-röthliches Pigment enthalten. Es liegt die Vermuthung nahe, darin einen Anfang von Blutgefälsen zu erblicken. Aufserdem enthält dasselbe noch andere strahlige grofse Zellen. auf die ich nicht weiter eingehen kann. M. Ehrenbergii bietet überhaupt bei seiner grofsen Durchsichtigkeit soviel Gegenstände der Untersuchung dar, dafs ich mich nicht entfernt rühmen kann, dasselbe erschöpfend zu kennen.

Die Sagittal-, Längs- und Ringfasern von M. Ehrenbergii lassen sich leicht isoliren. Die Säulchen sind sämmtlich an ihren Enden wurzelartig verzweigt (Taf. III, Fig. 4) und mit einem Protoplasmahof ungeben, in welchen niemals ein Kern vorkommt. Gehen wir nun zur zweiten Gruppe, in der Primitivbündel und Säulchen zugleich vorkommen, über. Bei den Poliadeen und Nemertinen (Taf. VI, Fig. 1 u. 3) sind die Primitivbündel der Längsschicht so deutlich entwickelt, dafs darüber kein Zweifel sein kann. Die Abbildung einer Polia (Fig. 3) zeigt die Primitivbündel nicht deutlich, da die Zwischensubstanz in der That äufserst gering ist. Am schönsten habe ich sie später bei einer grofsen Polia von Grönland gesehen.

Bei einigen Trematoden z. B. Tristoma und bei den Planarien kann man wegen der Kleinheit der Primitivbündel zwar auch noch zweifelhaft sein, ob die Bündel der Säulchen in einem hellen Raum liegen. Indefs glaube ich mich durch Anwendung von $\mathrm{H}$ a r t n a ck Immersion Nr. 9 davon überzeugt zu haben.

Das Protoplasma der Ring- und Diagonalschicht bei Planarien Trematoden und Poliadeen ist feinkörnig und enthält runde Kerne, nach aufsen geht es ohne bestimmte Gränze in eine Membran über, welche man gewöhnlich als die Base- 
mentmembran des Epithels betrachtet hat. Sie enthält, wie man am schönsten bei der erwähnten grofsen Polia sieht, Kerne und dringt zwischen die Basen der Epithelzellen ein. Da wo die Epithelien fehlen bildet sie wie die offenbar gleichwerthige Haut der Cestoden die Körperhülle.

Betrachten wir nun das Verhalten des Protoplasma bei Tristoma, den Planarien und Poliadeen nach innen, so läfst es sich leicht als eine Umhüllung der Sagittalfasern verfolgen. In dieser umhüllenden Schicht liegen häufig Kerne (Taf. VII, F. 8b). Um diese Protoplasmaschicht der Sagittalfaser liegt aber noch eine andere Substanz, die man zum Protoplasma rechnen mufs. In den seitlichen Ecken scheint dies zahlreiche Kerne einschliefsende Protoplasma homogen zu sein, mehr nach der Mitte hat es sich zu deutlichen Zellterritorien um die Kerne abgeschnürt (Taf. VII, Fig. 6). Bei Tristoma (Taf. VII, Fig. $8^{a}$ ) sind diese Zellen auch von festen Membranen umgeben, während bei den Planarien die Oberfläche der Zellen sich kaum von dem Inhalt unterscheidet.

Nemertes und Polia besitzt solche Zellen nicht, bei Nemertes ist dieses Protoplasma überhaupt bis auf eine breite Zone (Taf. VI, Fig. $1^{\text {b }}$ ) und den geringen Protoplasma-Rest zwischen den Ringfasern verschwunden oder in eine feste Bindesubstanz verwandelt. Die erwähnte Zone lälst bei den meisten Nemertes - wenigstens an Spiritusexemplaren keine Structur erkennen, an einer grofsen fast einen Centimeter breiten Nemertes von Surinam hat sie aber deutlich eine Structur wie das junge Bindegewebe von Wirbelthieren, das heifst wie eine helle Grundsubstanz mit vielen spindelförmigen Zellen und wird von Fasern und Membranen durchsetzt.

In der Gruppe endlich, wo die Muskulatur durchweg aus Primitivbündeln besteht, die Hirudineen und Onychophoren umfassend, ist das Protoplasma auf eine dünne bindegewebsartige Schicht zwischen den Primitivbündeln reducirt. In den Primitivbündeln stehen die Säulchen nur an der Peripherie. Macht man einen Querschnitt an Spiritusexemplaren, so kann man die Säulchen bei starker Vergröfserung leicht einzeln erkennen. An den bisherigen Abbildungen der 
Querschnitte der Primitivbündel tritt dies nicht deutlich hervor.

Die Entwickelungsgeschichte der Muskelfasern ist direct bis jetzt nur bei den Wirbelthieren - und namentlich beim Hühnchen - verfolgt. E ckhardt*) hat für die Muskulatur des Herzens und Wagener**) für die des Stammes, des Darmes und Herzens nachgewiesen, dafs die Fibrillen in einem Protoplasma auftreten und sich erst nachher zu Bündeln gruppiren. Man wird leicht finden, dafs bei den Plathelminthen diese zwei Stufen auch als bleibende Formen auftreten. Auch die verschiedenen Stufen der Ausbildung der Muskeln, welche ich selbst bei den Nemathelminthen beschrieben habe, lassen sich ebenfalls leicht als ein anderes Beispiel für dieses allgemeine Schema auffassen. Wenn nun auch diese Ansicht ein viel richtigerer Ausdruck der zu beobachtenden Thatsachen ist, als die älteren, welche bald die Muskelfibrillen selbst, bald das ganze Bündel direct aus Zellen entstehen liefsen, so möchte ich doch für alle diese niederen Entwickelungsstufen der Muskelfaser an das erinnern, was bei Gelegenheit der Cestodenmuskeln gesagt wurde, nämlich an die Möglichkeit, dafs ein scheinbar homogenes Protoplasma doch die einzelnen Zelllen bereits getrennt enthalten kann.

\section{Drüsengewebe.}

Die zwischen den Muskeln liegende Schicht ist im Vorhergehenden schon in soweit geschildert worden, als sie zur Muskulatur gehört oder indifferent bleibt. Darin ist nun eine überaus reiche Menge von Drüsen und ähnlichen Gebilden eingebettet. Den Cestoden fehlen diese Drüsen nach allen bisherigen Untersuchungen mit Ausnahme einiger in die Geschlechtsorgane mündenden vollständig, weil das Parenchym auf einer embryonalen Stufe stehen bleibt, bei Polia ebenfalls, aber aus einem anderen Grunde, das Protoplasma ist zu weit reducirt. Bei den Planarien durchzieht es am reichsten den

*) IX.

**) VIII. 
ganzen Körper, leider lälst es sieh hier wegen der Undurchsichtigkeit nicht im Leben untersuchen. Bei den Trematoden ist es ebenfalls reich entwickelt, und von Walter*) Leuckart**) und am genausten neuerdings von $\mathrm{Bl} \mathrm{umberg***)}$ beschrieben worden. Bei Bipalium und Nemertes sind die Drüsen auf die schon erwähnte Zone beschränkt zwischen der zarten äufseren Muskelschicht und der starken Längsschicht. Da ich diefs Gewebe am genausten von Mesostomum Ehrenbergii kenne und mich überzeugt habe, dafs man es nur an lebenden und so durchsichtigen 'Thieren mit einigem Erfolg untersuchen kann, will ich es von diesem Thier ausführlicher schildern und daran Vergleichungen mit den übrigen Ordnungen knüpfen.

\section{Stäbchen.}

Bekanntlich stehen bei allen Mesostomeen unter der Haut und zwar immer nahezu senkrecht darauf Stäbchen einer stark lichtbrechenden Substanz (Taf. VI, $1^{\text {b }}$ ). Aufserdem finden sich diese Stäbchen in grolsen birnförmigen Zellen nach innen von der rechtwinklich gekreuzten Schicht. Diese Zellen liegen einmal in einem grofsen Haufen jederseits von dem Nervenring, und dann rechts und links in den Seitentheilen zerstreut. Die Zellen des grofsen Haufens sind birnförmig und gehen in einen dünnen Strang naeh vorn aus. Es lassen sich jederseits zwei hinter einander liegende Gruppen unterscheiden, deren Ausläufer sich je zu einem gemeinsamen Strang vereinigen, von denen der eine oberhalb der andere unterhalb der vorderen Kopfnerven verläuft (Taf. III, Fig. 1 u. IV, Fig. 1). An der Kopfspitze treten die beiderseitigen Stränge durch eine Brücke zusammen. Die zerstreuten Zellen geben mehrere Ausläufer ab, welche sich weiter verästeln, bis sich schliefslich die Aeste an die Haut ansetzen. Jedes Stäbchen der Haut liegt in dem

*) XI, S. 270 .

**) XII, S. 470 .

****) XIII. 
Ausläufer einer Zelle. Diese Ausbreitung wurde schon genau von M. Schulze und Leuckart beschrieben. M. S chulz e*) hat auch die Stäbchen auf ihr Verhalten gegen verschiedene Reagentien untersucht.

Die Bedeutung dieser Stäbchen ist bereits vielfach erörtert worden. M. Schulze hält sie für Taststäbchen, Leu ckart für Nesselorgane.

Ich will zunächst einige neuere Thatsachen über dieselben mittheilen. Obgleich bereits M. Schulze und Leuckart angeben, dal's die Länge der Stäbchen sehr verschieden ist, so haben sie doch nur eine Art derselben beschrieben, welche immer vou einer ziemlich bedeutenden Gröfse und von einer starken Lichtbrechung ist. Es giebt noch eine zweite Art, welche aufserordentlich klein und nur mit den jetzigen besseren Mikroskopen $\mathrm{Hartnack}$ Immersion $\mathrm{Nr} .9$ deutlich erkennbar sind. Untersucht habe ich sie nur bei M. Ehrenbergii. Sie befinden sich in vereinzelten Zellen, welche auf der Bauchseite unter den Dotterstöcken und Hoden liegen

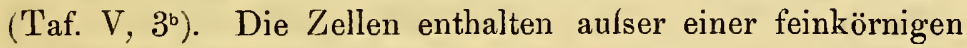
Substanz dicht gehäufte Massen dieser Stäbchen. Von den Zellen gehen Ausläufer, die sich verästeln und schliefslich an die Haut setzen. Die Ausläufer bilden wiederholt Anschwellungen, die ebenso wie die Auslänfer angefüllt sind mit Stäbchen. Die letzten Aeste schwellen keulenförmig an und enthalten in ihrem Ende eine helle kugelförmige Stelle, welche frei von Stäbchen bleibt. Beobachtet man die Stäbchen-Anhäufungen an einem ganz ruhigen unrerletzten Thiere, so sieht man darin mitunter eine plötzliche Bewegung, welche sich mit dem Wimmeln einer dichten Spermatozoenmasse vergleichen läfst. Wie die Mutterzellen so liegen auch die Ausbreitung und die Endigung der Ausläufer nur an der Bauchseite, man mufs deshalb zum Behuf der Untersuchung die Thiere mit dem Rücken auf das Objectglas legen.

Die gröfseren Stäbchen haben immer ein stumptes peripherisches und ein spitzes centrales Ende. In den Ausläufern

*) IV. 
liegen sie immer der Läuge nach, ebenso liegt die gröfste Menge in den Zellen. In den Zellen finden sich aber immer einige von bedeutender Länge mit sehr dünnem Ende, welches der Wand der Zelle entsprechend gekrümmt ist.

Es ist leicht zu bemerken, dafs die Anzahl der Stäbchen in den einzelnen Thieren sehr schwankt. Die Mutterzellen sind bald strotzend, bald weniger gefuillt. Ebenso ist die Anliäufung der Stäbchen in der Haut verschieden. Weiter findet man, dafs in einzelnen Thieren eine massenweise Neubildung stattfindet. Die Neubildung geht von Kugeln aus, welche sowohl in den Zellen (Taf. V, 3), wie in den Ausläufern auftreten und die für die grölseren Stäbchen grölser als für die kleineren sind. Weiter rückwärts habe ich diese Kugeln nicht verfolgen können. Die Kugeln verlängern sich und nehmen allmählich die definitive Gestalt an. Diese Neubildung findet in jedem Lebensalter statt, keineswegs vorzugsweise bei Jungen. Schon bei der Geburt sind sie reichlich damit ausgestattet. Aus diesem Verschwinden und wieder auftreten läfst sich schliefsen, dafs die Stäbchen zeitweise massenlıaft zu Grunde gehen, aber auf welche Weise? Darüber kann ich eine befriedigende Antwort geben. Wenn man ein 'Thier auf das Objectglas gebracht und mit dem Deckglas, welches immer mit Siegellackfuifschen versehen sein mufs, bedeckt hat und untersucht nun das Objectglas zu den Seiten des Thieres, so findet man sehr häufig (Taf. III, 5n) Stränge von verschiedener Länge, bald gestreckt, bald wellenförmig gekrümmt. Sie enthalten einen stïrker licktbrechenden Faden, umgeben von heller homogener Substanz. Das eine Ende ist abgerundet, das andere spitz. Lis giebt Exemplare, welche nicht eins dieser Körper entleeren, während andere das Objectglas auf weite Stellen damit überzielien. Diese Fäden sind die hervorgeschnellten gröfseren Stäbchen. Das Abschiefsen sieht man allerdings nur äufserst schwierig, wahrscheinlich reicht das Bedecken mit dem Deckgläschen hin, un das Thier dazu zu reizen. An einem Exemplar ist es mir aber doch gegliickt, den Moment der Entladung und zwar am Vorderende zu sehen. Es waren nur wenig Stäbchen, 
sie hatten zuerst das gewöhnliche Ansehen als aus homogener stark lichtbrechender Substanz bestehend, nach wenigen Secunden traten aber alle Veränderungzn zu der eben beschriebenen Gestalt ein. Drückt man ein beliebiges Stäbchen aus dem Thiere heraus, so nimmt es niemals diese Gestalt an, sondern es platzt einfach auseinander, langsam in Wasser, schneller in Essig, Mineralsäure und Kali. Eine Resistenz gegen Kalilauge wie die Stäbchen ron M. tetragonum wach M. Schulze - und wie ich bestätigen kann - haben, besitzen die Stäbchen von M. Ehrenbergii nicht. Aus diesen Beobachtungen geht hervor, dafs diese Stäbchen eine gewisse Reife erlangen und dann erst auf einen Reiz herausgeschleudert werden. Aulser diesen gröfseren Fäden finden sich ('`af. III, 5 $5^{b}$ kleinere und sehr zarte, über deren Gestalt und Lage im Thier ich nichts weifs. Ebendaselbst $5^{\text {d }}$ ist eine Zeichnung, die man ebenfalls auf dem Objectträger findet. Ich vermuthe darin die Producte der Entladung der kleineren Stäbchen. Vielleicht ist jede der ovalen Figuren hervorgegangen aus der einmaligen Entladung einer Endanschwellung.

Es liegt nahe, daran zu denken, dals diese Fäden zu irgend etwas benutzt werden. Ich habe zuerst geglaubt, zum Fang; allein so oft ich auch Daphnien untersucht liabe, welche die Mesostomeen eben im Kampf bewältigt hatten, niemals fand ich daran die Fäden. Eine andere Vermutlıung bat sich bei mir gebildet, dals sie bei der Begattung als Reizmittel eine Art Liebespfeile verwendet werden. Dafür spricht der Umstand, dafs alle Exemplare, welche 1-2 Tage isolirt gehalten wurden, die Entladung am schönsten zeigen und zwar gleichgültig, ob die Thiere hungerten oder reichlich mit Futter verschen waren. Dals sie beim Fang nicht verbraucht werden, ist also sicher, und ihre Anhäufung während der Isolirung würde also wohl für die zweite denkbare Gebrauchsweise sprechen. Ist nun auch die Natur dieser Stäbchen um vicles aufgeklürt, so bleibt doch noch manche Flage ungelöst. Will man dieselben als ein Drüsensecret betracliten, so mufs man jerlenfalls zugeben, dal's es als solches neu und eigenthümlich ist. Mit Nesselorganen haben sie vielleicht eine Ver- 
wandschaft, allein doch sicher eine sehr entfernte, die sich nur vermuthen, nicht beweisen lïist. Würden die Stäbchen nicht ausgeworfen, so würde kein Beobachter anstehen, sie für Enden sensibler Nerven anzusehen. Insofern hat M. Scli ulze Recht gehabt. Ich will noch anführen, dals sie in essigsaurem Ammoniak die Neigung haben, solche Querstreifen oder Plättchen zu zeigen, wie die Retinastäbchen.

Dafs die Stabchen aus den Zellen allmählich nach der Haut nachrücken, ist wahrscheinlich, einen directen Beweis habe ich aber nicht finden können. Ein Theil entsteht sicher direct unter der Haut. Die langen Stäbchen, welche gekrümmt in den Zellen liegen, rücken niemals in die langen Ausläufer, sie werden wahrscheinlich durch kurze Ausläufer an der Bauch- und Rückseite, die man wegen der flachen Gestalt des Thieres nicht sehen kann, entleert. Denn die längeren der ausgeschlenderten Körper können nur von den längsten Stäbchen herrühren.

Das Vorkommen solcher oder älnlicher Stäbchen ist unter den Rhabdocölen aufser bei den Mesostomeen nur noch erwähnt bei Vortex (M. Schulze). Die eigentlümlichen Körper im Schwanz von Monocelis, welche mitunter Stäbchen genannt werden, scheinen doch davon wesentlich verschieden. Unter den übrigen Plathelminthen fehlen sie den Trematoden, Cestoden und Poliadeen. Beiden Süfswasser-Planarien findet man in dem Epithelium helle ellipsoidische Körper. Sie stehen darin ähnlich wie die oben beschiriebenen Körper aus Mesostomum mit denen sie auch, wie M. S chul ze (a. a. O.) nachwies, die leichte Löslichkeit in Essigsäure und eine starke Resistenz gegen Kalilauge gemein haben. Indefs fiuden sie sich auch (Taf. VII, Fig.6) in der Drüsenschicht und bilden dort auf Querschnitten eine Zone, welche in einiger Entfernung von der Körperwand verläuft, einzelne finden sich auch zwischen der Zone und dem Epithel. Es läfst sich daraus vermuthen, dafs sie sich im Innern des Körpers bilden und von da aus in das Epithel treten. Die Bildungszellen selbst habe ich jedoch nicht darstellen können. In Carminlösung färben sich diese Körper 
sehr schön roth, in Glycerin und Alkohol schrumpfen sie etwas, nehmen aber in Kalilauge ihre Gestalt wieder an.

Bei Bipalium liegen die Stäbchenzellen, welche sich im Alkohol recht gut erhalten haben, in der erwähnten Parenchymzone. Sie haben mehrere nach der Haut gehende Ausläufer, deren Epithelzellen reichlich damit gefüllt sind. Sie sind braun gefärbt und geben der Haut die dunkele Farbe. Auf der Mitte der Bauchseite verläuft ein breiter heller, etwas vorstehender Streifen, der sich auch durch einen dichten Pelz langer Wimpern auszeichnet. Derselbe enthält keine Stäbchen, es fehlen auch in dieser Gegend die Stäbchenzellen (Taf. VII, Fig. 7).

Bei Nemertes haben die Stäbchen am meisten und deutlichsten den Character des Drüsensecretes. Sie ragen viclfach aus dem Epithel hervor und das hervorragende Ende ist zerbröckelt und allem Anschein nach in Zerfall begriffen. Nach Innen in der Parenchymzone findet sich die Stäbchensubstanz in langen Gängen gestreckt (Taf. VI F. 1), gewunden oder wellig verlaufend. Dazwischen finden sich ähnliche dünnere Gänge, welche nicht die braune Stäbchensubstanz enthalten, aber durch Carmin tief roth gefärbt werden. Man darf wohl annehmen, dafs sie die jüngeren Stufen der Stäbchenbildung vorstellen. Ueber die zellulare Zusammensetzung dieser Parenchymzone ist schon oben gesprochen worden. An der schon erwähnten grofsen Nemertesspecies ist die Haut mit tiefen Querrunzeln bedeckt, welche nur in den Vertiefungen ein Epithel tragen, während es sonst fehlt. Das Epithel ist mit schönen glatten wie mit feinkörnigen Stäbchen erfüllt, die Bildungstätte derselben liegt in der schon oben beschriebenen bindegewebigen Parenchymzone, wo man sie als Gänge, welche mit einer feinkörnigen Masse erfüllt sind, erkennt. Erst in der Haut nehmen die Stäbchen die characteristische Gestalt an.

\section{Spinndrūsen.}

Die Mesostomeen, namentlich M. E. und M. tetragonum. haben die Eigenschaft, einen fadenziehenden Schleim abzu- 
sondern. Sie benutzen dieselbe, man kann sagen in einer wahrhaft mörderischen Weise, zum Fang kleiner und grofser Thiere.

Ihre Nahrung besteht in kleinen Lumbricinen, Entomostraceen, Hydrachnen, Diptercn- und Notenectalarven, welche sie, wie schon $\mathrm{F}$ o cke beschreibt, mit dem Schlundkopf aussaugen, so dafs das leere Skelett übrig bleibt. Die Entomostraceen ziehen sie allen andern vor. So wie ihnen eins zu nahe kommt, geben sie ihm und zwar auch denjenigen, welche sie nicht fressen wollen, einen leichten Schlag mit dem Vorderende und sofort ist es mit Schleim bedeckt und bestrebt sich vergeblich zu entrinnen. Man findet in den Gefälsen, worin man dic Mesostomeen aufbewahrt, einzelne und ganze Haufen von Daphniden und Cyclopiden an den Wänden und auf dem Boden durch den zuerst ganz unsichtbaren Schleim festgebannt. Mit den Notonectalarven lassen sie sich selbst nicht in diesen so leichten Kampf ein, sondern fangen sie in einem Netz, welches auf der Oberfläche und durch das Wasser gesponnen wird. Sind keine Notonectalarven im Gefäls, finden sich auch die Netze nicht. Ephemerenlarven haben sie nie angefallen oder gefangen, Corcthralarven nur im Nothfall und wie mir schicn nicht immer mit Erfolg. Untereinander verschonen sie sich selbst im Hunger, ebenso verschmähen sie Planarien.

Auch in der Weise benutzen sie diese Eigenschaft, dafs sie einen Faden an einer Lemna befestigen und sich daran den Kopf nach unten aufhängen. Oft findet sich eine ganze Gesellschaft in dieser Stellung.

Dieser Schleim scheint nicht aus einer begrenzten Stelle des Körpers auszutreten, sondern aus sehr feinen Oeffinungen, welche über die ganze Banchfläche zerstreut stehen, die ich aber allerdings nicht sehen konnte. Berührt man die Thiere mit einem festen Körper, so kann man immer einen Faden ausziehen.

Als Bildungsstätten dieses Schleimes kann man die Zellen betrachten (Taf. III, I), welche in der Mittellinie der Bauchseite vom Schwanz bis zur Geschlechtsöffnung und vorn 
zwischen dem Kopfende und der vorderen Hirncommissur stehen. Sie besitzen einen deutlichen Kern und stehen durch breite Ausläufer mit einander in Verbindung. Aufserdem haben sie noch dünne vielfach verästelte Ausläufer von grofser Feinheit, welche man nur mit Hartnack Nr. 9 sieht. Die Zellen selbst aber namentlich die Ausläufer enthalten überaus feine Körnchen, welche die Molekularbewegung zeigen. Diese feinsten Ausläufer sind nur in gut genährten Exemplaren deutlich mit Körnchen erfüllt, dann aber namentlich an jungen Exemplaren sehr schön zu sehen. Sie verbreiten sich zwar über die Bauchseite des ganzen Körpers, im Schwanz aber bilden sie scheinbar ein dichtes Netzwerk, ohne dafs jedoch, wie ich nach sorgfiiltiger Untersuchung annelımen mufs, eine quere Verbindung zwischen den Ausläufern stattfindet. Die Zellen selbst führen die Körnchen nur in geringer Menge, dagegen zahlreiche kleine Kugeln, welche gekrümmte stäbchenförmige Körper enthalten (Taf. V, $2^{\mathrm{b}}$ ). Weiter unten wird die Besprechung der Speichelzellen uns Gelegenheit geben, auf dicses merkwürdige Drüsensystem zurïckzukommen.

Bei M. obtusum (Taf. IV, Fig. 1) sieht man im Schwanz zahlreiche weitere und engere Räume mit feinen, in Molekularbewegung begriffenen Körnchen, welche wohl ebenfalls zu einem solchen Drüsensystem gehören.

Das Vorkommen von fadenziehenden Secreten ist bei den Plathelminthen schon anderweit bekannt. Leydig beschreibt es von Piscicola *) als das Secret einzelliger Drüsen, welche in der Kopf- und Fulsscheibe sich befinden. Aehnliche Drüsen findet man bei den übrigen Hirudineen über die ganze Haut verbreitet. Die Hautdrüsen, welche Lieber$\mathrm{k} u ̈ \mathrm{~h} n$ bei Prorhynchus stagnalis entdeckte, werden ebenfalls hierher gehören (Taf. VII). O. Schmidt**) fand bei Poly. celis cornuta hinter der Geschlechtsöftuung eine Höhlung, in welche zwei andere flaschenartige Höhlen münden, deren Wände muskulös sind. Da das Gefäls, in welchem diese

*) III, S. 109.

**) XIV, S. 32. 
Species eine Nacht zugebracht hatte, mit einer spinnewebsartigen Haut erfüllt war, so vermuthet er in der Höhlung Spinndrüsen. Unter den Nemertinen kommt nach Keferstein $*$ ) das Spinnen bei Cephalothrix longissima vor.

\section{Drüsen der Geschlechtsorgane.}

Ein Packet einzelliger Drüsen liegt (Taf. III, Fig. 1 k) bei M. Ehrenbergii zu beiden Seiten der Geschlechtsöffnung, ihre Ausführungsgänge münden in den Ausführungsgang der Eierstöcke. Dieselben Drüsen finden sich bei M. obtusum (Taf. IV, 1). Andere Drüsen führen in die Scheide des Penis. O. Schmidt**) hat dieselben bei sechs Mesostomeen gefunden und lärst sie alle in die Saamenblase d. $h$. das innere Lumen des Penis münden. Bei Mesostomum Ehrenbergii habe ich überhaupt keine in den Penis mündende Drüse gesehen, wohl aber bei M. obtusum und tetragonum. Allein gerade bei letzterer fand ich das Secret immer in dem Raum zwischen dem Penis und seiner Scheide. Auch die Planarien besitzen eine solche Drüse. Ich habe sie an Querschnitten von Süfswasserplanarien untersucht. Sie umhüllen den Ausführungsgang der Geschlechtsorgane und breiten sich auf der Rücken- und Bauchseite flächenartig aus. Die Ausführungsgänge der Zellen strahlen vorzugsweise nach der Geschlechtsöffnung zu. Das Secret ist in Alkohol bräunlich und färbt sich nicht in Carmin.

Auch O. Schmidt hat dieselben Drüsen bei Planaria gonocephala ***) und Dendrocoelum lacteum $\dagger$ ) abgebildet und läfst sie auch hier in den Penis münden. Nach meinen Querschnitten ist dies aber olne Zweifel nicht der Fall. Keferstein $\dagger$ ) bildet dieselbe Drüse bei Leptoplana tremellaris und Eurylepta argus ab und zwar in die weibliche

*) XV, S, 64 .

**) XVIII, S. 41.

***) XIV, Taf. IV, Fig. 4.

†) XVII, Taf. IV, Fig. 10.

††) XVI, Taf. I, Fig 1; Taf. II, Fig. 1 und 3. 
Geschlechtsöffnung mündend. Seine Annahme, dafs sie Eiweifs für die Eier absondert, dürfte wohl kaum bewiesen sein.

In die Geschlechtsorgane mündende Drüsen kommen offenbar allen Plathelminthen zu. Bei den Trematoden werden sie erwähnt von Leuckart*) und Blumberg**) bei den Cestoden von Sommer und Lando is ***). Dafs diese Drüsen ein Secret zur Bildung der Schaale liefern, wie man allgemein annimmt, halte ich nicht blofs für unbewiesen, sondern auch für unwahrscheinlich. Wir werden bei Gelegenheit des Dotterstocks näher darauf eingehen. Speciell bei Mesostomum Ehrenbergii münden in den Uterus, wo die Schaalenbildung vor sich geht, überhaupt keine Drüsen.

\section{Speicheldrüsen.}

Diese in den Mund sich öffnenden Drüsen kommen bei rhabdocölen Turbellarien sehr häufig vor. Wir wollen dieselben bei M. Ehrenbergii genauer betrachten. Die Speichelzellen liegen hier zu beiden Seiten des Mundes (Taf. III, Fig. 1 i). Von jeder Seite führen zwei Stränge von Ausführungsgängen nach dem Schlundkopf, deren einer seitlich, der andere weiter nach hinten mündet. Die Zellen hängen unter einander deutlich zusammen, während andererseits feine Stränge sich in das Parenchym erstrecken (Taf. V, Fig. 3 a). Ess stellen diese Drüsen Zellennetze mit feinen Ausläufern vor. Sie verhalten sich also ähnlich wie die eben genannten Spinndrüsen, nur liegt bei den Speichelzellen der Zusammenhang der Theile klarer vor Augen. Da die seitlichen dünnen verästelten Ausläufer derselben nicht Ausführungsgänge, sondern secretorische Theile sind, so dürften auch bei den Spinndrüsen die seitlichen Ausläufer secretorisch sein und die Ausführungsgänge vielleicht kurze auf der Bauchseite mündende Stränge

*) XII, S. 483 .

**) XIII.

***) VII, S. 60. 
sein. Die Ausläufer der Speicheldrüsen sind übrigens nicht so reichlich wie die der Spinndrüsen.

Dieses Zellennetz, welches das ganze Parenchym mit einem Capillarsystem von secretorischen Kanälen durchziehet, kann man wohl als eine neue Form des Drüsengewebes bezeichnen.

Die Ausfülırungsgänge gehen deutlich in den Schlundkopf. Wie sie aber sich öffnen ist schwer zu enträtbseln. Um die Schwierigkeit zu verstehen müssen wir auf den Bau des ganzen Schlundkopfes eingehen. Der zwiebelförmige Schlundkopf liegt in einer Höhle, welche ihn scheidenartig umgiebt, und ist nur auf der oberen Seite dieser Hölle festgewachsen, indem er dort die Oeffnung des Darmes umgiebt. Die Drüsen müssen also von der Rückseite her in den Schlundkopf eintreten. Deutlich muskulös ist der Schlundkopf nur an seinem Lumen und an seiner unteren Fläche und zwar sind weit abstehende Längs- und Ringfasern in einfacher Lage (Taf. VI, Fig. 5) vorhanden. Das ganze Parenchym des Schlundkopfes wird durch kernhaltige radial gestellte Zellen von länglich prismatischer Gestalt gebildet. Nun sind die Zellen dicht mit ähnlichen Secreten wie die Speicheldrüsen erfüllt. Es müssen also jene Zellen der Speicheldrüsen direct mit den Zellen des Schlundkopfes zusammenhängen. Daraus erklärt sich auch, warum die Speichelstränge sich nicht weiter in den Schlundkopf verfolgen lassen. Bei den Nematoden kommt eine ähnliche Einlagerung von Drüsen in die Muskelsubstanz des Oesophagus vor *).

II. Ehrenbergii giebt uns die Gelegenheit, die Vorgänge in den Drüsen aın lebenden Thier viel genauer zu verfolgen, als an den höheren Thieren, an denen die Physiologen ihre Untersuchungen gewöhnlich ausschliefslich zu machen pflegen. Man bemerkt, dafs die secretorischen Zellen nicht untergehen. So genau ich darauf meine Aufmerksamkeit richtete, fand ich keine Spur und Anzeige davon. Auch in den Drüsen höherer Thiere liegt also keine Veranlassung vor, in allen Füllen

*) X, S. 192 . 
an den Untergang von Zellen zu denken. Die Zelle verliert einen Theil ihrer Substanz ohne unterzugehen und ersetzt denselben durch Wachsthum. Ich habe einen ähnlichen Vorgang in dem Uterus von Ascaris megalocephala und lumbricoides *) beschrieben, wo das Secret in der Weise gebildet wird, dafs die Epithelzellen keulenartige Auswüchse bilden, welche sie abstofsen, ohne unterzugehen.

\section{Wassergefäfssystem.}

Ueber das Wassergefälssystem habe ich nur einige Beobachtungen betreffend M. Ehrenbergii mitzutheilen. Der Verlauf der Hauptstämme, ihre feinere Verzweigung und die Mündung der zwei Hauptstämme in die Scheide des Schlundkopfes hat L e uckart**) bereits genau beschrieben. In den gröfseren und kleineren Stämmen stehen einzelne wimpernde Stellen, wie sie in den Wassergefäfsen der Platbelminthen überall vorkommen. Man nimmt nach dem Vorgang von v. Siebold \% jetzt allgemein an, dafs dieselben aus den von $\mathrm{C}$ zermak entdeckten undulirenden Membranen bestehen. M. Ehrenbergii macht in dieser Beziehung eine Ausnahme. Wie man sich leicht ïberzeugt, wenn man die Bewegung durch Zusatz von Jodlösung allmählich absterben lälst, werden diese Stellen von einer Reihe einzelner Wimpern gebildet, welche auf einem plattenartigen Vorsprung stehen (Taf. III, 6); da man denselben und folglich auch die Wimperreihe gewöhnlich im Profil sieht, erhält man allerdings zuerst das Bild einer undulirenden Membran. Die feinsten Ausläufer des Wasscrgefälssystems sind mit becherförmigen Anhängen besetzt, in welchen je eine einzelne lange Wimper steht. Man möchte glauben, dafs dies offene Ausmündungen wären wie sie Le y dig von Clepsine complanata und Thiry von den Ammen Cercaria macrocerca allerdings in einer ganz andern Gestalt beschrieben hat. Eine Oeffnung läfst sich aber an unsern

*) X, S. 257.

**) V, Taf. IX.

***) XIX, S. 361 . 
Bechern nicht erkennen. Von ihren Enden geht immer ein dünner Faden ab (Taf. III, 6).

\section{Rüssel.}

Rüssel kommen bei den Plathelminthen häufig und in verschiedener Gestalt und Function vor, dal's wir dieselben als eine dieser Klasse eigenthümliche Bildung betrachten können. Dieselben sind entweder geschlossene oder offene Röhren.

Bei den geschlossenen Formen ist ein länglich muskulöser Schlauch vorhanden, von dessen Spitze ein Muskel nach rückwärts geht, welcher das Vorderende rückwärts in das Hinterende zurückzieht und einstülpt; der eingestülpte Theil, der während der Ausstïlpung aus dem Körper hervorragt, kann als der Rüssel, und der Theil, welcher immer im Körper bleibt, als die Rüsselscheide betrachtet werden. Rüssel wie Rüsselscheide sind immer muskulös. Als eine sehr tief stehende Entwickelungsstufe dieser Form kann wohl auch das Rostellum der Taenien betrachtet werden, über welches wir jetzt durch $\mathrm{Nitsch}^{*}$ ) genauere Aufschlüsse erhalten haben. Der von Nitsche als elastisches Kissen bezeichnete Theil des Rostellum ist übrigens auch muskulös und scheint mir gleichwerthig mit dem bei Taenia undulata auftretendem innerem Sack zu sein. Es liegt ferner nahe, den äufseren Sack als die Scheide, den inneren als den Rüssel zu betrachten. Um die Aehnlichkeit mit dem Rüssel der Tetrarhynchus, Nemertes und der Poliadeen herzustellen, fehlte nur der Retractor.

Dem Rüssel der Taenien schliefst sich vielleicht am nächsten der der Prostomeen an, dem der Retractor ebenfalls fehlt. Leider hat man denselben noch nicht genauer untersucht.

Uebersehen hat man bisher gänzlich den Rüssel von Stenostomum, derselbe ist allerdings sehr rudimentär und deshalb bis jetzt für ein Wassergefäls gehalten worden.

*) $\operatorname{xxIx}$. 
Allein der helle, vom Kopf bis zum Schwanz laufende Kanal (Taf. IV, Fig. 2) gleicht durch seine Lage und die muskulöse Beschaffenheit seiner Wand vollständig der Rüsselscheide eines Nemertes. Auch enthält er vorn deutlich einen inneren Strang, welcher weiter hinten an der Rüsselscheide angewachsen ist, der unzweifelhaft dem Rüssel entspricht. Hervorgestreckt habe ich ihn allerdings nicht gesehen.

Der Rüssel der Poliadeen und von Nemertes unterscheidet sich bekanntlich dadurch, dafs ersterer ein Kalkstilet trägt. Allein auch die Lage der beiden Organe ist aufserdem noch in jeder Hinsicht verschieden. Die Rüsselscheide von Nemertes wie der von Stenostomum und Prostomum ist an der Kopfspitze angewachsen. Der Mund liegt weiter rückwärts. Bei den Poliadeen dagegen liegt der Mund in der Kopfspitze und die Rüsselscheide ist im Innern der Mundhöhle angewachsen. Der Rüssel öffnet sich also durch den Mund.

$\mathrm{Zu}$ den Formen mit ausstülpbaren Rüsseln gehört auch der merkwürdige Ropalophorus (D i esing, Distoma coronatum Rudolphi), welcher im Darm brasilianischer Didelphysarten vorkommt, ferner Gasterostomum fimbriatum.

Ein fleischiges, aber wie mir scheint nicht aus- und einstülpbares, sondern nur hervorstreckbares fleischiges Organ liegt in der Mundhöhle von Dinophilus und wahrscheinlich auch von Bipalium. Doch kann ich über letzteres mich nicht mit Bestimmtheit aussprechen, da ich überhaupt nur ein Exemplar dieses seltenen Thieres besitze.

Die zweite Form der Rüssel, diejenige, mit offenen Röhren kommt einmal bei dem Penis vor, dann bei dem Rüssel der aus dem Grund der Mundhöhle bei Planaria, Clepsine und den Opistomeen vorgestreckt werden kann. Diese letztere dürfte verwandt sein mit den zwiebel- und tonnenförmigen Formen des Schlundkopfes, welche bei den Rhabdocölen so häufig sind und diese wiederum führen uns zu den einfachsten Formen des Rüssels, nämlich den Saugnäpfen.

Dafs der sogenannte Rüssel von Prorhynchus ein Penis ist und mit dem Rüssel der Poliadeen nichts gemein hat, wird 
aus den im Anhang mitzutheilenden Untersuchungen Li e ber$\mathrm{k} \ddot{\mathrm{u} h \mathrm{n}}$ 's hervorgehen.

\section{Nervensystem.}

Während bei allen Thierklassen das Centralorgan des Nervensystems sehr allgemein einen Ring darstellt, ist bei vielen Plathelminthen ein solcher Ring bis jetzt nicht bekannt.

Bei Trematoden und Planarien sprechen die meisten Autoren ausschliefslich von einer vorderen Commissur. Nur W a Ite r erwähnt für Amphistoma einen geschlossenen Nervenring. Auch in den vielen genauen Abbildungen der Rhabdocölen finden wir immer nur eine vordere Commissur angegeben. Indel's kann man sich bei M. Ehrenbergii überzeugen, dal's die beiden von der vorderen Commissur rückwärts laufende Stränge (Taf. III, Fig. 1 n) durch eine helle, wenig Zellen enthaltende Commissur hinter dem Schlund verbunden sind. Bei genauer Untersuchung dürfte man wohl auch sonst eine hintere Commissur finden.

Die Hauptstämme des peripherischen Nervensystems liegen bei allen Plathelminthen mit Ausnahme der Hirudineen. wo sie sich in der Mittellinie des Bauches vereinigen, seitlich. Selbst bei den Onychophoren*), welche den Hirudineen so nahe stehen, sind sie noch durch einen ziemlichen Abstand getrennt. Segmentirte Formen verhalten sich in dieser Beziehung gleich wie unsegmentirte, z. B. Malacobdella $* *$ ). Diese seitlichen Hauptstämme lassen sich bei Nemertes und den Poliadeen schön auf Querschnitten untersuchen und zeigen sich dann (Taf. VI, Fig. 1-3) zusammengesetzt aus einem mittleren feinkörnigen, weder Kerne noch Zellen enthaltenden, durch Carmin sich nicht färbenden Theil, welchem zu beiden Seiten Zellen aufliegen. Bei Polia enthält der mittlere Strang aufser der feinkörnigen Substanz dicht gedrängt aufserordentlich feine Fibrillen, welche sowohl längs als quer

*) XXIV.

**) $\mathrm{XXV}$. 
laufen. Dieselben Fibrillen und Zellen sind auch im Hirn zu fiuden. Bei Nemertes habe ich ebenfalls quer- und längslaufende Fibrillen gesehen, aber viel undeutlicher. Die Gangliensubstanz vertheilt sich demnach hier auf die ganze Länge des Stammes.

Peripherische Aeste kann man bis zu einer aufserordentlichen Feinheit bei M. Ehrenbergii verfolgen, ihre nähere Untersuchung war aber so schwer, dafs ich davon abstand. Bei Nemertes habe ich die peripherischen Aeste nicht finden können. Bei den Poliadeen sind sie aber sehr leicht schon unter der Loupe zu sehen, ihre Anordnung ist ganz ähnlich wie bei Malacobdella. Die Aeste sind sehr dick und gleich dem Stamm aus Fibrillen und Zellen zusammengesetzt. Da die Aeste bei Polia zu beiden Seiten in gleichen Abständen abgehen, so habe ich die Poliadeen zu den segmentirten Formen gerechnet. Der Mangel von Ganglienanschwellungen wird um so weniger dagegen geltend gemacht werden, als wir auch aus einer andern Klasse, der Nemathelminthen, ein Beispiel kennen, nämlich bei Lumbricus, wo die Ganglienzellen gleichmärsig über den Hauptstrang vertheilt sind. Die peripherischen Aeste der Poliadeen theilen sich weiter und dringen noch in einer ziemlichen Dicke durch die Muskelschicht und Basementmembran bis zum Epithel.

Das Nervensystem der Cestoden ist bis auf das Ganglion, welches G. R. Wagener*) bei sehr grofsen Tetrarhynchusspecies gefunden hat, gänzlich unbekannt. Es besteht aus zwei oder mehreren Hauptstämmen, welche symmetrisch seitlich gelegen sind und sich im Vorderende durch eine Schlinge verbinden. Bereits $\mathrm{Nitsche}{ }^{* *}$ ) hat darauf aufmerksam gemacht, dafs die Stränge, welche nach aufsen von dem Stamm des Wassergefäfssystems liegen, unmöglich ebenfalls Wassergefälse sein können, wie die früheren Beobachter angenommen haben. Eine Meinung über ihre Bedeutung weifs er auch nicht aufzustellen. Ich labe dieselben

*) XXII, S. 94 und Taf. IV und V.

*:*) XXIX. 
schon seit längerer Zeit beobachtet und bin durch die Aehnlichkeit, welche sie durch ihre Lage und ihr ganzes Ansehen mit dem Nervensystem der Nemertinen haben, zu der Ueberzeugung gekommen, dafs sie die Nerven der Cestoden darstellen. Wegen ihrer Lage und ihres Ansehens verweise ich auf die Abbildung von Nitsche, Sommer und Landois. Macht man bei einer Ligula Querschnitte vom Kopfende, so kommt man nach wenig Schnitten auf die Anastomosc. Die Nervensub. stanz vereinigt sich und bildet eine ziemlich breite Brücke zwischen den zwei Hauptstämmen. Zellen und Fibrillen sind darin nicht wahrzunehmen. Ich untersuchte eine Species aus Cyprinus brama, welche einen tiefen dorsoventralen Einschnitt in der Mitte des Kopfes hat, die man gewöhnlich als Ligula simplicissima bezeichnet, und eine andere Species aus Gasterosteus aculeatus, deren Körper deutlich gegliedert ist und in der Mitte des Kopfes die Spur eines Saugnapfes trägt. Wegen der Einfachheit des Kopfes findet man hier die Anastomose am leichtesten und sichersten. Taenia perfoliata, welches keinen Hakenkranz und kein Rostellum besitzt, zeigt die Anastomose noch schöner und zwar 18-22 Querschnitte von der Kopfspitze entfernt. An dieser Species habe ich das Nervensystem in der höchsten Ausbildung gefunden. Es enthïlt die Anastomose Kerne und Fibrillen, auch die zwei seitlichen Hauptstämme, welche nach rückwärts gehen, sind nach der Rück- und Bauchseite zu deutlich mit Zellen belegt, so dafs sie vollständig den Hauptstämmen eines Nemertes gleichen.

In die Glieder habe ich das Nervensystem von T. perfoliata noch nicht weiter verfolgt, da sich hierbei viele Schwierigkeiten entgegenstellen wegen der sonderbaren Form, nämlich dünner Platten, die sie annehmen und wegen der Ausbreitung der Geschlechtsorgane - Schwierigkeiten, die bei einiger Anstrengung wohl zu überwinden sein werden.

Unmittelbar vor der Anastomose ändert sich die Muskulatur, es tritt ein stark muskelöses Kreuz auf, dessen Arme auf die Mitte der vier Seiten des Kopfes treffen. 
Auch bei Tetrarhynchus, wie ich mich bei mehreren Species überzeugt habe, liegen die beiden Hauptstränge seitlich, sie laufen bis nahe an die Kopfspitze und vereinigen sich durch eine sehr sclöne kernhaltige Anastomose. Wie bei Taenia perfoliata liegt vor derselben ein Kreuz von Muskelfasern. Das grofse Ganglion W a gner's ist wahrscheinlich diese Anastomose, welche nur durch die Präparation aus der natürlichen Lage gebracht war. Bei Taenia crassicollis mülste die Anastomose unterhalb des Rostellum liegen. Sie hat wahrscheinlich die Form eines Ringes. Das Rostellum ist nahe seinem hinteren Ende von Nervensubstanz umgeben. Es gelingt aber nicht, die Nervensubstanz als einen zusammenhängenden Ring zu sehen, da eine Menge Muskelfasern vom Rostellum in radialer Richtung nach der Leibeswand verlaufen.

Die Lage des Centralnervenringes ist im ganzen Thierreich meist so, dafs der Schlund durch denselben hindurchtritt, dafs sogar die Ausdrücke „Nervenring“" und „Schlundring" als gleichbedeutend gebraucht werden. Die Plathelminthen zeigen aber, dafs die Lage um den Schlund, ja die Ringform nur der specielle Fall eines allgemeineren Gesetzes sein mufs. Sowohl bei Nemertes, als bei den Poliadeen wird der Nervenring nicht vom Schlund, sondern vom Rüssel durchsetzt. Bei einem Theil der Cestoden ist der dem Centralorgan entsprechende Theil eine Brücke. Vielleicht kann man sich die Entstehung des Nervenringes in folgender Weise vorstellen. Die niederste (vielleicht anch die embryonale) Form des Nervensystems besteht in zwei Strängen, welche durch eine Brücke verbunden sind. Entsteht nun in der Mitte des Kopfes über der Brücke eine Neubildung, sei es ein Rüssel, ein Munddarm oder ein anderer Ausführungsgang, so durchbohrt er die Brücke und macht sie dadurch ringförmig.

Ein eigenthümliches Sinnesorgan besitzen die Gattungen Nemertes und Stenostomum (Taf. IV, Fig. 2) in den Kopfspalten. Ihrer Anlage nach unterscheiden sie sich nicht von den Sauggruben der Bothriadeen unter den Cestoden und bei 
Stenostomum sind sie nicht wesentlich höher entwickelt. Aber bei Nemertes sendet die hintere innere Ecke der Kopfspalte einen engen, mit langen Wimpern besetzten Kanal nach dem Nervenring, wo sich derselbe zu einem ganz in Gangliensubstanz eingebetteten Knäuel windet.

Auch Polia besitzt solche Grübchen, die man mit denen von Nemertes zusammengestellt hat, die sich aber wesentlich davon unterscheiden. Die Mundöffnung der Poliadeen ist eine wimpernde Längsspalte, auf deren Hinterende rechtwinklich eine wimpernde Rinne von Seite zu Seite verläuft. Eine seitliche Kopfspalte existirt also nicht. Die wimpernde Stelle, an welche sich, wie $Q$ uatrefages*) gefunden hat, ein Nerv begiebt, ist offenbar das seitliche Ende dieser Rinne.

\section{Darmkanal.}

Der Darmkanal sämmtlicher Plathelminthen besteht aus einer Schicht Zellen. Auch Mesostomum, wie alle Rhabdocölen, und die Planarien machen davon keine Ausnahme. Die Zellen besitzen Kerne und enthalten bei Mesostomum schon früh helle Räume, in deren Innern feste Concretionen schweben, wie sie als Secretbläschen aus der Leber der Mollusken und anderwärts bekannt sind. Ich würde die cellulare Zusammensetzung des Darmes nicht besonders hervorheben, wenn nicht $\mathrm{O}$. Schmidt in seinem vortrefflichen Lehrbuch der vergleichenden Anatomie (S. 101) selbst in der neusten Auflage die Ansicht wiederholte, dals der Darmkanal der Rhabdocölen und Dendrocölen von einem verdauenden Protoplasma erfüllt wäre.

\section{Zur Pathologie von M. Ehrenbergii.}

M. Ehrenbergii ist häufig von einem Parasiten heimgesucht, welcher die Hoden und Speichelzellen bewohnt. Taf. III, Fig. 7 giebt die verschiedenen Stadien seiner Entwickelung an. Derselbe ist bis c kugelrund und die speichen- 
artigen Radien stehen nach allen Seiten. Zuletzt umgiebt er sich mit einer Cyste, welche von polyedrischen sich treffenden Leisten besetzt ist und welche Fig. d nur im Durchsclnitt angiebt. Im Herbst 1871 starben fast alle Thiere an diesem Parasiten, im Jahre 72 ist er nur an einem Thiere aufgetreten.

Verletzungen erträgt unser Thier sehr gut. Ich theilte zwei grofse Exemplare kurz hinter der Geschlechtsöffnung in zwei Theile. Die hinteren Stücke gingen bald zu Grund, aber die vorderen lebten weiter. Das eine, welches ich am längsten - 10 Tage - am Leben liefs, hat sogar noch einige Wintereier gebildet.

Der Tod geht in vielen Fällen, die ich beobachtete, in der Weise vor sich, dafs die Thiere sich plötzlich zusammenziehen und in ein Häufchen verwandeln. Darin findet man immer die vollkommen isolirten Sagittalfasern wohl erhalten, während die anderen Elemente schneller zu Grunde gehen.

\section{Entwickelungsgeschichte.}

\section{Arten der Eier nnd Begattung.}

Schon Pallas beobachtete, dafs M. Ehrenbergii zweierlei Eier besitzt, helle durchsichtige, welche sich im Uterus und dunkele hartschaalige, welche sich im Wasser entwickeln. O. S c h midt hat noch zwei Rhabdocölen beschrieben, M. lingua und M. (Schizostomum) productum, welche lebendige Junge gebären und, wie ich für $M$. lingua angeben kann, auch hartschaalige Eier legen. Die iubrigen Mesostomeen bilden wie die anderen bekannten Rhabdocölen nur hartschaalige Eier. Ueber das Gesetz, welches das Auftreten dieser zwei Arten der Eibildung beherrscht, haben die trüheren Beobachter keine Untersuchungen angestellt. L euckart nimmt an, dafs die Bildung der beiden Eiarten neben einander stattfinden kann.

Ich sammelte im Sommer und Herbst 1871 eine bedeuttende Menge hartschaaliger Eier, hielt sie in Gefälsen und konnte daran die folgenden Beobachtungen anstellen. Wir 
wollen zunächst den ganzen Verlauf der Libildung schildern und dann zur Untersuchung der einzelnen Punkte übergehen. Die zuerst braunen Eier werden schon im Herbst schwarz und gehen aus der Halblkugelform in die Kugelform über. Der Embryo ist bereits im November ziemlich fertig, mit Wimpern bedeckt, noch etwas dicker von Gestalt. Das Ganglion ist sehr grofs, der Mund mit dem Schlundkopf steht bis zum Ausschlüpfen nahe dem Schwanz. Man sieht daraus, dafs Formen, wie Mesostomum obtusum, die embryonale Körpergestalt zeitlebens behalten. Die ersten Embryonen schlüpfen bereits im Februar aus, andere später, die letzten sogar erst im Juni.

Sowie die Jungen die Länge von 7-8 $\mathrm{mm}$ erreicht haben, treten auch die Eier und zwar zunächst nur durchsichtige in den Uterus ein. Der Uebergang findet in wenigen Tagen statt und hört dann auf. Sämmtliche Junge sind nach drei Wochen gleichmälsig ausgebildet und werden mindestens an demselben Tag, wenn nicht in kürzerer Zeit geboren. In selteneren Fällen schon am Ende der Trächtigkeit, aber gewöhnlich erst nach dem Geburtsact beginnt die Bildung der hartschaaligen Eier und dauert bis zum Tode des Thieres. Ist ein Individuum einmal in die Periode der dunkeln Eier eingetreten, so bildet es nie wieder helle. Wir werden sehen, dafs dies unmöglich ist. Die Jungen beginnen bereits nach wenig Tagen wieder in derselben Weise helle Eier zu bilden und nach deren Geburt dunkele. So folgen sich die verschiedenen Generationen je nach Futterzustand langsamer und schneller bis in den November. Kein Embryo schlüpft aus einem dunkelen $\mathrm{Ei}$ vor dem nächsten Frühjahr. Wir sind demnach berechtigt, die hellen Eier Sommereier, die dunkelen lartschaaligen Wintereier und die daraus entstehenden Thiere Sommer- und Winterthiere zu nennen.

Die Vermuthung, welche zunächst lag, war die, dafs wie bei den Rotatorien, Aphiden, Daphniden u. s. w. die Sommereier ohne Befruchtung, die Wintereier mit Befruchtung entstehen würden. Allein die Untersuchung lehrte, dafs bereits vor der Bildung der Sommereier nicht blofs 
die Hoden, sondern auch der Ausführungsgang des Eierstocks mit Sperma erfüllt waren. Auch den Einwand konnte ich beseitigen, dafs dieses Sperma keine Verwendung finde, denn ich sah in den Sommereiern selbst die Saamenfäden (Taf. VI, Fig. 5 a). Nachdem sich diese Ansicht als haltlos erwiesen, schien es als sehr natürlich, anzunelmen, dafs die Sommereier durch Selbstbefruchtung, die Wintereier durch gegenseitige Befruchtmg entwickelt würden. Ich habe zu diesem Zweck eine lange Reihe von Isolationsversuchen gemacht. Es hat sich als Resultat ergeben, dafs bei den isolirten d. h. jungfräulichen Thieren der Ausführungsgang des Eierstocks sich ganz in derselben Weise mit Sperma erfïllt, wie bei begatteten und dafs sowohl Sommer- wie Wintereier durch Selbstbefruchtung entstehen könuen. In vier Experimenten gelang es aus isolirten Winterthieren, in zwei aus isolirten Sommerthieren Sommerthiere zu ziehen.

Indels wäre es möglich gewesen, dafs die bei der Isolirung sich bildenden Wintereier keiner Entwickelung fähig sind. Der Versuch lehrt aber das Gegentheil. Die aus isolirten Müttern zahlreich erhalteneı Wintereier haben sämmtlich Embryonen erzeugt. Ja ich kounte sogar nachweisen, dafs wemn eine durch Selbstbefruchtung entstandene Generation von Sommerthieren Wintereier durch Selbstbefruchtung erzeugt, auch diese entwickelungsfähig sind.

Es ist somit für Mesostomum Ehrenbergii festgestellt, dafs die Begattung nicht unbedingt nöthig zur Entwickelung der Eier ist, sondern dafs die Selbstbefruchtung hinreicht.

Die Möglichkeit der Selbstbefruchtung hat v. Siebold schon früher bei den Trematoden behauptet, indem er ein drittes direct in den Uterus führendes vas deferens sah, dessen Vorkommen auch von Thaer und Aubert bestätigt, nenerdings aber von $\mathrm{S}$ ti e da und $\mathrm{Bl} \mathrm{l}$ m berg bestritten worden ist.

Ueber den wirklichen Eintritt der Selbstbefruchtung und seine Folgen lälst sich bei den parasitischen Plathelminthen nichts entscheiden, da man dieselben schwerlich wird isoliren können.

Um so mehr fühlte ich mich veranlafst diese Frage 
bei M. Ehrenbergii weiter zu verfolgen. Denı mit dem oben erwähnten Resultat ist dieselbe keineswegs erledigt. Künstliche Isolirung zeigt uns zwar, dals die Selbstbefruchtung zur Entwickelung der Eier vollkommen hinreicht, allein es entstehen weitere Fragen : welches ist der normale Vorgang und welchen Einfluls auf die Fruchtbarkeit hat die Selbstbefruchtung? Die schönen Untersuchungen der Botaniker haben gezeigt, dal's die Selbstbefruehtung der Pflanzen die Fruchtbarkeit erheblich mindert und dal's die Selbstbestäubung des Pistills dureh verschiedenartige Vorrichtungen unmöglich gemacht ist. Es hat sich nun gezeigt, dal's anch bei den Hermaphroditen des Thierreichs ähnliche Erscheinungen eintreten.

Selbstbefruchtung findet normal nur für die Sommereier. der Winterthiere statt.

Wenn man Individuen von Sommer- und Winterthieren jeden Alters beobachtet, wird man sie überaus häıfig in Begattung finden. Der Act dauert wohl eine halbe Stunde und lälst sich deshalb kaum übersehen. Allein niemals habe ich junge Winterthiere zu der Zeit, wo ihre Sommereier in den Uterus treten und auch eine Woche darauf in Begattung gesehen. Es ist ihnen oftenbar unmöglich. Zwar besitzen sie einen Penis, derselbe ist aber überaus klein und unentwickelt, dal's man denselben erst bei starker Vergrölserung (HartnakImmersion 9) mit Sicherheiterkennen kann. Er enthält auch eine Spur von Saamen, doch gewifs nicht zur Begattung, sondern nur weil die Ausführungsgänge des Hodens hineinmünden und der Saamen den Penis passiren muls, um zum Eierstock zu gelangen. Ist der Eintritt der Sommereier in den Uterus beendigt, so findet man den Penis leer und vollständig verschrumpft. Nach einiger Zeit erst wächst er aus, füllt sich prall mit Saamen und wird nun läufig gebraueht. Ganz anders verhält sich der Penis bei jungen Sommerthieren, so wie die Spermatozoen gebildet sind, ist auch der Penis fertig und prall mit Saamen gefüllt.

Um sich von der Richtigkeit dieser Beobachtungen zu überzeugen muls man die Thiere aus Wintereiern erziehen. 
Dafs Selbstbetruchtung der Sommereier von Winterthieren allein normal ist, lälst sich auch aus anderen Erscheinungen erkennen. Die isolirten Winterthiere bekommen durchweg ihre volle Anzahl Sommereier, bei isolirten Sommerthieren dagegen erfolgt der Eintritt der Sommereier in den Uterus sehr unregelmälsig und nur in lïngeren Pausen. In einem Fall waren sie eingetreten und verschwanden plötzlich spurlos. In einem andern Fall war die Entwickelung soweit fortgeschritten, dafs die Augenpunkte der Embryonen bereits sichtbar waren, als die Mutter sammt den Kindern starb. Ueberhaupt während Isolirung den Winterthieren nicht schadet, ist sie für die Gesundheit der Sommerthiere sehr verderblich. Nur selten gliickt es isolirte Sommerthiere am Leben zu erhalten. Meist bekommen die Thiere eine gelbe Farbe, schwimmen und bewegen sich nicht, hören auf zu fressen und sterben. Giebt man ihnen zur rechten Zeit eineı Genossen, so werdeu sie schnell wieder gesund. In mehreren Fällen ist mir aber gelungen, vollständig isolirte Sommerthiere am Leben zu erhalten.

Es besteht somit bei M. Ehrenbergii ein regelmäfsiger Wechsel zwischen einer Fortpflanzung durch gegenseitige und durch Selbstbefruchtung. Schon früher gelang es mir einen ähnlichen Procefs bei der Nematoden-Gattung Leptodera nachzuweisen. Dieser Generationswechsel darf dem Steenstrup'schen Generationswechsel d. h. dem Wechsel einer Fortpflanzung ohne Befruchtung und einer oder mehreren Fortpflanzungen mit Befruchtung verglichen werden. Wie man sieht kann derselbe bei getrenntem Geschlecht und bei Hermaphroditen auftreten.

Wenden wir uns nun zu der Frage, ob die Verhinderung der gegenseitigen Begattung die Fruchtbarkeit beeinflufst. Dafs diese Frage bejaht werden mul's ergiebt sich schon aus dem angeführten Umstand, dafs die Isolirung auf die Gesundheit und die Fortpflanzungsfähigkeit schädlich einwirkt. Diese Gefahr ist aber nur während der Zeit der Sommertracht vorhanden, ist die Periode der Wintertracht eingetreten, so bleiben die Individuen vollkommen gesund. Allein 
auf eine andere, sehr entschiedene Weise wird die Fruchtbarkeit durch die Isolirung eingeschränkt.

Sommerthiere, welche in isolirten Müttern aufwachsen, erzeugen nur Wintereier.

Der Versuch wurde in der Weise angestellt, dafs die Brut einer isolirten Mutter in einem Gefäl's gehalten wurde; sämmtliche Junge zeugten nur Wintereier. Ein Experiment will ich beispielsweise vollständig mittheilen. Ein am 28. Mai jungfräulich isolirtes Individuum gebar am 21. Juni 40 Sommerthiere. Davon haben am 4. Juli ohne vorher Sommereier zu bilden bereits 4 Exemplare ein Winterei. Die ganze Brut setzt die Wintereibildung fort und stirbt am 21. Juli. Ein Individuun derselben Brut wurde vollständig isolirt, hatte an 4. Juli ein Winterei, am 8. 3 und 4, am 10. 5 und 6, am 11. 6 und 7, am 16. 12 und 12 Wintereier. Am 20. gestorben mit Hinterlassung von 31 Wintereiern.

Diese ansschliefsliche Bildung von Wintereiern tritt sowohl an der Brut von isolirten Winterthieren, wie an der Brut von isolirten Sommerthieren auf. Da die Selbstbefruchtung der Winterthiere physiologisch ist, so kann die Selbstbefruchtung nicht die Ursache der Winterbrütigkeit sein, sondern ein anderer Umstand, welcher mit der Isolirung in einem entfernteren Zusammenhang steht. Es besteht derselbe darin, dafs durch die Verhinderung der Begattung der Geburtsact verzögert oder, um es anders auszudrücken, das intrauterine Leben verlängert wird. Genaue Zahlen kann man nicht anführen. Die aufmerksame Beobachtung zeigte aber, dafs diese isolirten Thiere gegen Ende der normalen Tragzeit sich auffallend quälten. Setzte ich ihnen einen Genossen zu, so wurde die Begattung bald vollzogen und noch im Laufe des Tages erfolgte die Geburt. Um die Wichtigkeit der Begattung für diese Thiere zu begreifen muls man in Betracht ziehen, dal's sie dieselbe überaus häufig vollziehen. Eine vollständige Isolirung ist gar nicht nöthig, um sich von der Richtigkeit des oben aufgestellten Satzes zu überzeugen. Ich habe zweimal Mütter isolirt, welche mit einer durch Begattung erzeugten Nachkommenschaft trächtig waren. Bis 
zur Geburt verflossen nur 6 und 5 Tage, aber die ganze Brut erzeugte nur Wintereier.

Einer weiteren Untersuchung mufs es vorbehalten bleiben, die Eigenschaften der Winterthiere festzustellen, welche durch Selbstbefruchtung entstanden sind.

Die Zahl der Sommereier, welche ein Winterthier erzeugt, beträgt $40-50$. Die Sommerthiere erzeugen viel weniger, günstigen Falls 20, die letzten im November doch noch 10-12, aber auch weniger 4-6. Die Zahl der Eier ist rechts und links immer gleich oder höchstens um 1 verschieden. Die Tragzeit ist etwa drei Wochen.

Die Zahl der Wintereier eines Individuums beträgt bei den kräftigsten Thieren etwa 30. Die Wintereier lassen sich am unverletzten Thier mit blofsem Auge erkennen. Mit grofser Regelmäfsigkeit bildet sich täglich 1 höchstens 2 Eier in jedem Uterus. Das erste tritt immer im rechten Uterus auf, das zweite im linken und so fort.

Die ersten Winterthiere fangen mit der Eibildung etwa 2 Wochen nach dem Ausschlüpfen an. Doch will ich diese Zahl nicht als absolut gelten lassen, da im Anfang meiner Versuche die Fütterung unzureichend war und daraus möglicherweise eine Verzögerung entstand. Einzelne Winterthiere gebaren Ende Mai, die Geburt der grölsten Menge fand Mitte Juni statt. Die Wintereier werden zwar mitunter einzeln nach aulsen entleert, die grölste Menge wird aber erst durch den Tod der Mutter frei.

Als Beispiel will ich den Lebenslauf des schon oben erwähnten isolirten Winterthieres, welches gesund bis an sein Ende blieb und meiner Schätzung nach am 20. Mai geboren war, weiter mittheilen. Es starb am 24. Juli mit Hinterlassung von 24 Wintereiern, hatte also 54 Tage gelebt.

Während bei den Winterthieren nach der Geburt die Entwickelung der Genitalien sehr langsam fortschreitet, geht dieselbe bei den Sommerthieren im Juni aufserordentlich schnell. Einige Tage nach der Geburt ist bereits Saamen im Penis.

Das Wachsthum wird selbst bei reichlicher Fütterung erst während der Periode der Wintereier vollendet. Beim 
Beginn der Sommertracht haben sie kaum die halbe Länge, bei der Geburt sind sie nahezu fertig. Man kann deshalb, wenn ein noch auf etwa halber Gröfse stehendes Thier Wintereier bildet, erkennen, dafs es die Sommertracht übersprungen hat. Aulser der künstlich erzeugten Winterbrütigkeit kommt anch eine natürliche an Individuen, welche zur Begattung reichlich Gelegenheit hatten, gar nicht selten vor.

Schlecht gefütterte Thiere bleiben klein, holen aber bei guter Fütterung das Versäumte nach. Thiere, welche ich im Freien fing, hatten niemals die Grölse meiner Zuchtthiere.

Zur Vergleichung will ich einige Beobachtungen über die Eibildung von $M$. tetragonum mittheilen. Es bildet nur Wintereier und beginnt damit schon wenn es $6 \mathrm{~mm}$ Länge hat. Die Zahl derselben betrug in einem Individuum 120, woraus man auf eine Lebensdauer von über 60 Tage schliefsen kann. Es bilden sich wenigstens täglich zwei Eier und zwar eins in jedem Uterus. Die Thiere waren im September sämmtlich todt. Einzelne Junge schlüpften schon im November aus und begannen wieder mit Eibildung. Mangel an Begattung beeinträchtigt die Eibildung nicht. Ein Individuum, welches allerdings schon begattet war und bereits 12 Eier besals, wurde isolirt, es starb mit Hinterlassung von 66 Eiern.

Da die Tümpel, in welchen die Mesostomeen sich aufhalten, im Sommer eintrocknen, so untersuchte ich, ob die Wintereier das Eintrocknen ertragen. Ich liefs Eier von Mesostomum Craci (O. Schmidt) zwei Tage lang aut dem Boden eines grofsen Glasgefäl'ses vertrocknet stehen, sie sind sämmtlich unentwickelt geblieben. Die Austrocknung werden also wohl nur Eier überleben, welche etwas tiefer in Schlamm eingebettet sind.

Auch tropische Wärme können die Eier von Mesostomum Craci und Ehrenbergii nicht vertragen. Eine Anzahl derselben, welche ich in der Hoffnung ihre Entwickelung zu beschleunigen in das Warmhaus des botanischen Gartens stellte, ging bereits nach wenig Wochen unter. 


\section{Dotter und Dotterstöcke.}

Ueber die Bedeutung der nur bei den Plathelminthen und zwar sehr häufig vorkommenden Dotterstöcke *) und ihres Productes stehen sich zwei Ansichten gegenüber. Die einen glauben, dafs der Dotter ein Nahrungsstoff des Eies ist, die anderen glauben, dafs der Dotter sich mit einem Keimbläschen zum Ei vereinige und als solches den Furchungsprocefs durchlaufe. Diese letztere halte ich durch die früheren Beobachtungen schon widerlegt. Die jetzt über den Dotter von Mesostomum Ehrenbergii mitzutheilenden werden aufser andern auch dazu dienen diese Widerlegung zu unterstützen.

Die Dotterstöcke von M. Ehrenbergii bestehen aus langen Strängen, an welchen in regelmälsigen Abständen Büschel von Zellreihen stehen. M. tetragonum gestattet wegen seiner bedeutenderen Dicke die Lage der einzelnen Geschlechtsorgane besser zu bestimmen. Der Uterus liegt am Bauch, der Hoden am Rücken, die Dotterstöcke in der Mitte. Es sind jederseits zwei Stränge vorhanden, einer vor, der andere hinter der Geschlechtsöffnung, welche beide bogenförmig nach der Geschlechtsöffnung hinziehen. Diese Stränge sind keineswegs Ausführungsgänge, sondern nur Leitbänder (gubernacula). Die vordersten $B \ddot{s}$ schel sind die reifsten, sie rücken wahrscheinlich durch Verkürzung der Leitbänder immer näher an den Geschlechtsraum, und treten dort, wie ich glauben mufs, plötzlich in den Uterus.

Dafs der Dotter aus Zellen entsteht, weifs man schon längst. Ed. van $B$ en ed en **) in seiner umfassenden Arbeit über die Dotter giebt auch an, dafs er die Kerne der Dotterzellen bis in den Uterus verfolgt hat. Wir werden sehen, dafs die Dotterzellen wenigstens bei M. Ehrenbergii bis zur Vollendung des

*) Es ist von Reichert vorgeschlagen, statt Dotter den Ausdruck "Eiweifs ${ }^{4} \mathrm{zu}$ gebrauchen. Ich gebe gern zu, dafs der letatere etwas correcter ist. Aber da dieser Dotter weder dem Dotter noch dem Liweifs des Hühnerei's vollkommen entspricht und ich um die schon ohnehin verbreitete Sucht der Namengebung nicht weiter zu verbreiten auch den Namen Biogenfüssigkeit nicht anwenden will, so bediene ich mich des alten.

*) XXIII, S. 23. 
Embryo unversehrt am Leben bleiben. Die Dotterzellen umhüllen sofort das Ei und die Spermatozoen und die Masse umgiebt sich mit einem Häutchen. Diese Eihaut oder das Chorion hat man bisher allgemein als ein Secret des Uterus betrachtet. Die Vorstellung, dafs feste Eihüllen nothwendigerweise von dem

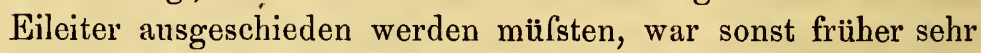
verbreitet, wahrscheinlich weil man dem einfachen Ei nicht die Fähigkeit zutraute so complicirte Schaalen zu bilden. Ich habe für die Nematoden bewiesen, dafs ihre Eischaalen sämmtlich von dem Ei selbst gebildet werden, und für sämmtliche Eischaalen der Wirbelthiere kann man jetzt nach den Untersuchungen von Nathusius wohl mit Gewifsheit annehmen, dafs sie ebenfalls vom Ei selbst herrühren. Auch hier halte ich die Annahme, dafs die Schaale vom Uterus gebildet wird, für unbewiesen. Niemals bemerkt man auf der Innenwand desselben einen darauf hinzielenden Vorgang. Das Ei wird durch die Bewegung vielmehr hin und her geworfen und es ist viel wahrseheinlicher, dafs die Haut eine Bildung der Dotterzellen ist. Bei den Sommereiern ist dies sogar kaum anders möglich. Während der Entwickelung nimmt dasselbe nämlich an Umfang bedeutend zu. Seine Dicke, die allerdings nur gering ist, bleibt sich aber gleich. Sie ist also immer im Wachsthum. Wie ist das denkbar von einem Seeret des Uterus? Dazu kommt noeh, dafs die Sommereier sich oft gegenseitig berühren und keineswegs immer ganz vom Uterus umhüllt sind.

Die Zellen des Dotterstocks sind in der ersten Entwickelungszeit und so lange die Ablage der Sommereier dauert hell, nur mit Körnchen einer das Licht wenig brechenden Substanz erfüllt. Sowie die Sommerperiode vorbei ist, findet in den Zellen eine ganz allmählich fortschreitende Erfüllung der Dotterzellen mit stark lichtbrechenden kleineren oder grölseren Körnern statt (Taf. VI, Fig. 10). Es ist jetzt wohl allgemein bekannt, dafs dies nicht Fettkörper, sondern Eiweifskörper sind, die sich aber durch einen sehr geringen Wassergehalt auszeichnen. Setzt man eine Zelle, z. B. die Spermatozoen der Nematoden, in eine concentrirte Lösung 
von Kochsalz oder Zucker, so wird sie sofort kleiner und fettartig conturirt.

Die Bildung der dunkelen Wintereier ist also kein beliebig zu unterbrechender Procefs, sondern sie ist eine weitere Entwickelung des Dotterstocks selbst. Diese Entwickelung beschränkt sich nicht auf den Dotterstock, sondern ergreift auch den Eierstock. In den Eiern werden während der Winterperiode zwar nur sparsam, aber doch deutlich feine dunkele Körner gebildet, welche den Sommereiern fehlen (Taf. VI, Fig. 4).

Die Bildung der zweierlei Eier kanı man demnach auch so bezeichnen : Eier die sich in einem jüngeren Alter des Thieres ablösen werden Sommereier, die in einem späteren Wintereier. Die meisten Rhabdocölen bilden allein Wintereier, nur einige Mesostomeen Sommer- und Wintereier. Es wäre aber denkbar, dals es auch solche giebt, die nur Sommereier bilden, $d$. h. sterben vor der Periode der Wintereier.

Es ist auffallend, dafs bei allen Thieren, welche Sommer- und Wintereier bilden, Rotatorien, Daphniden, Aphiden, die Sommereier einen hellen Dotter, eine dünne weiche Schaale und vivipare Entwickelung, die Wintereier dunklen Dotter, harte und dickere Schaale und ovipare Entwickelung haben. Zwischen diesen Bedingungen dürfte also wohl eine Beziehung stattfinden. Die Befruchtung oder Nichtbefiuchtung braucht, wie man sieht, auf den Zusammenhang der drei Bedingungen keinen Einflul's zu haben.

Die Nematoden, deren Eier mir gut bekannt sind, können uns dazu dienen, diese Beziehungen zu finden. Ich habe bereits früher bemerkt, dals die Eier derselben auffallende Unterschiede zeigen und habe sie eingetheilt in hart- und weichschaalige. Ebenso giebt es dunkele und helle Eier. Gewifs ist, dafs alle hellen Eier (Filaria papillosa, Cucullanus elegans, Trichina spiralis) sich schnell d. h. schon im Uterus entwickeln. Die dunklen Eier verhalten sich ungleich. Die Eier von Ascarisarten, welche in warmblütigen Thieren leben, entwickeln sich niemals in Uterus, sondern erst im Freien, 
andere dunkle Eier, z. B. von Leptodera nigrovenosa und Nematoxys, entwickeln sich schon im Uterus. Was die Schaalenbildung anbelangt, so ist allerdings durchgehends die Schaale dunkler Eier härter als die heller Eier. Allein die Dicke ist davon unabhängig. Es giebt dunkle Eier mit dünnen und dicken Schaalen. Dafs ein Ei mit concentrirtem Eiweifsgehalt auch eine wasserarme harte Schaale absondert, wird man leicht zugeben. Die Dicke wird offenbar davon abhängen, wie lange das Ei in dem Stadium der Schaalenbildung bleibt. Bei den Nematoden ist dieses Stadium immer schon vor der Bildung des Furchungsprocesses abgeschlossen. Fin helles $\mathrm{Ei}$, welches sich schneller entwickelt, wird deshalb nur zur Bildıng einer dünnen Schaale gelangen, ein dunkles Ei zu einer dickeren. Wenn aber besondere Verhältnisse die Entwickelung des dunklen Ei's beschleunigen, so kommt es auch nur zu einer dünnen Schaale. Bei den Echinorhynchen dauert auffallender Weise die Schaalenbildung noch während des Furchungsprocesses fort, in Folge dessen haben sie eine sehr dicke Schaale, obgleich das Ei hell ist. Ein dunkles $\mathrm{Ei}$ enthält aber die Bedingungen vereinigt, vermöge deren es sich wahrscheinlich langsamer entwickeln, eine harte und dickere Schaale bekommen wird.

Die Zellen des Dotters bleiben bei M. Ehrenbergii unversehrt, bis der Embryo sich vollständig entwickelt hat. Die Durchsichtigkeit der Sommereier - erlaubt die Veränderungen der Zellen während dieser Zeit zu verfolgen. Anfangs umgeben sie das Eichen wie ein dickes Epithel. Bald aber nehmen sie Flüssigkeit auf und bilden grofse Vacuolen, welche jedoch nur nach der Mitte zu liegen. Nach aufsen unter der Eihant bildet die Substanz der Zellen eine ununterbrochene Schicht (Taf. VI, Fig. 6). Protoplasmabewegungen habe ich an ihnen nicht gefunden. Mit der Zeit treten Dotterkörner ähnliche Bildungen in ihnen auf und die Kerne nehmen deutlich an Gröfse zu. Ist der Embryo fertig, so zerreibt er die Zellen durch seine Bewegungen und frifst sie wahrscheinlich auf. Die Bedeutung der Dotterzellen ist aber eine viel bedeutendere, als die eines Futters für das 
Ende des Embryolebens. Aller Nahrungsstoff der zul dem Embryo tritt, mufs durch sie hindurch, sie sind lebendige Wesen, die man vielleicht am ersten mit Blutkörperchen vergleichen kann und erinnern in dieser Beziehnng an die beweglichen Zellen, welche im Innern der Ascidieneier vorkommen.

Die Bedeutung des Dotters als lebendige Zellen hat man bisher noch nicht erkannt, obgleich es bei den Eiern der Süfswasserplanarien sehr leicht ist. Die Dotterzellen derselben bilden eine zusammenhängende Schicht, welche der Schaale ansitzt und zeigen selbst im Wasser noch lange Zeit die bekannten prachtvollen Contractionserscheinungen, welche meines $W$ issens v. Siebold zuerst kennen gelehrt hat.

Ueber den Uterus von Mesostomum will ich nur bemerken, dafs derselbe vor dem Beginn der Eiablage ein kurzes, durch seine Muskelfasern contrahirtes Rohr ist, welches von der gemeinsamen Geschlechtsöffnung ausgeht. In dem Maafse wie Eier hinein gelangen, weitet er sich aus und sendet an seinem Ende einen langen Zipfel nach vorn und hinten, so dafs er T förmig wird. Sind die Sommerthiere geboren, behält er seine Gestalt. Bei den Individuen, welche die Sommerperiode überspringen, ist der Uterus anfangs auch unfertig und weitet sich erst durch den Eintritt der Wintereier aus, bietet also für die Erkennung solcher Individuen ein sicheres Merkmal.

\section{Furchungsprocefs (Taf. VI, 5, 6, 7).}

Den Furchungsprocefs von M. Ehrenbergii habe ich nur an Sommereiern verfolgt, die Wintereier bieten viel grölsere Schwierigkeiten dar. Das reife Ei besitzt einen grolsen von einer Flüssigkeit erfüllten Kern und einen Nucleolus, welcher wieder einen kleinen von Flüssigkeit erfüllten Raum enthält. Nachdem die Saamenfäden in das Ei gedrungen sind, beginnt der Kern sich zu verändern. Seine Umrisse verschwinden scheinbar und es bleibt nur der Kernkörper (Fig. 5 a) sichtbar. Allein auf Essigsäurezusatz waren auch die Umrisse des Kernes sichtbar und zwar erscheinen sie vielfach gefaltet und verbogen. Endlich verschwindet auch der Nucleolus und 
der ganze Kern hat sich in einen Haufen feiner, lockig gekrümmter, nur auf Zusatz von Essigsäure sicltbar werdender Fäden verwandelt. (Taf. VI, Fig. $8 \mathrm{c}$ zeigt dasselbe Stadium an einem anderen Orte). An Stelle dieser dünnen Füden treten endlich dicke Stränge auf, zuerst unregelmälsig, dann zu einer Rosette angeordnet, welche in einer durch den Mittelpunkt der Kugel gehenden Ebene (Aequatorialebene) liegt (Fig. 5 b u. c). Dem Anschein nach bilden diese Stränge den Umrifs einer flachen, vielfach eingebuchteten Blase; indefs überzeugt man sich bei genauerer Ansicht, dafs ilır Contur an den inneren Winkeln der Zipfel vielfach unterbrochen ist. Die in dem Ei befindlichen Körnchen haben sich in Ebenen gruppirt, welche sich in einer senkrecht auf die Aequatorialebene und in deren Mittelpunkt stehenden Linie schneiden (Meridianebenen). An dem frischen Ei ist von dieser Anordnung wenig zu sehen, da der Brechungscoefficient der Stränge und Körnchen fast dem des Protoplasma gleicht. Durch $\mathrm{Zu}$ satz von Essigsäure heben sie sich aber kräftig ab. Wenn die Zweitheilung beginnt, haben sich die Stränge vermehrt und so geordnet, dals ein Theil nach dem einen Pol, der andere nach dem andern sich richtet (Fig. 5 d). Endlich schnürt sich das Ei ein und die Stränge treten in die Tochterzellen. Die Reihen der Körnchen strecken sich in die Länge und lassen sich aus der einen Zelle in die andere verfolgen. Die polare Anordnung der Körnchen findet man bekanntlich auch beim Furchungsprocels der Ascidien und Seeigel.

Nach Vollendung der Zweitheilung löst sich der strangförmige Kern auf und ein bläschenförmiger, mit feinen Granulationen erfülter Kern tritt wieder an die Stelle. Wenn die Theilung weiter fortschreiten soll, macht jeder Kern und die Zelle von neuen dieselbe Veränderung durch wie bei der Zweitheilung und auf diese Weise wird die Eizelle in einen Haufen von Zellen mit granulirtem Kern (Fig. 5 f) verwandelt, aus welchen sich schliefslich der Embryo aufbaut. Bis zur Viertheilung sind die Dotterzellen noch hinreichend durchsichtig, um alle Veränderungen im unverletzten $\mathrm{Ei}$ zu erkennen. Von da ab mufs man die Eihülle sprengen und die 
Zellen ausfliefsen lassen. Man findet dann in jedem Ei Zellen auf den verschiedensten Stufen, da schon die Viertheilung an den beiden Mutterzellen nicht gleichzeitig eintritt. Niemals aber findet man Zellen mit granulirtem Kern in Theilung, da derselbe vorher immer eine Metamorphose eingehen mufs.

Diese Beobachtungen geben uns einen schon längst erwünschten Aufschlufs über die Zelltheilung und besonders den Furchungsprocefs. Sie zeigen uns zum erstenmal deutlich, welche umständliche Metamorphose der Kern (das Keimbläschen) bei der Zelltheilung eingehen kann. Diese Metamorphose ist offenbar nicht bei jeder Zelltheilung nothwendig, aber sehr wahrscheinlich tritt sie immer dann ein, wenn der Kern scheinbar verschwindet. Wäre hier der Kern nicht zufällig grofs und die Zelle durchsichtig, so würde man wahrscheinlich auch annehmen, dal's wie in anderen Fällen der Kern verschwindet.

Diese Art des Furchungsprocesses kommt auch bei anderen Plathelminthen vor. Der erste und einzige 'Trematod, welchen ich darauf untersuchte, Distoma cygnoides, zeigte deutlich ähnliche Kerne aus strahlenförmig angeordneten Strängen bestehend (Fig. 7). Genanere Untersuchungen sind bei Trematoden wegen der Kleinheit der Eier sehr schwierig.

Dal's man überhaupt zweiArten derZelltheilung unterscheiden mufs eine solche bei der der Kern während der Theilung eine Metamorphose eingeht, und eine solche, bei der der Kern seine Gestalt beibehält, wird sich in den folgenden Abschnitten bei der Bildung von Saamen und Eiern zeigen. Auch sonst findet sich bei Mesostomum am entwickelten Thier diese eigenthümliche Kerntheilung *). Es liegen am Darm Zellen von einer ungewissen Bedeutung und zwar sind sie daran vermittelst eines dünnen Fadens befestigt, welcher in einiger

*) Der Geschlechtsapparat entwickelt sich aus einem Haufen Zellen mit granulirtem Kern, deren Vermehrung in derselben Weise wie beim Furchungsprocesse erfolgt. Eben so kann man diese Vermehrungsweise an jungen Dotterstöcken sehen. 
Entfernung vom Darm anschwillt und dort einen grofsen Kern birgt, der aus feinen Körnchen besteht. Diese Zellen sind mitunter in Theilung, und bieten dann ganz dasselbe Bild, wie die sich furchenden Eizellen (Taf. VI, Fig. 11).

\section{Eibildung ('Taf. VI, 4).}

Der Eierstock der Mesostomecn ist ein unpaares, immer rechts gelegenes Organ. Sein blindes Ende enthält in einem hellen Protoplasma eine Lage Kerne, welche den embryonalen Character behalten, nämlich kugelförmig granulirt und mit Nucleolus (a) versehen sind. Sie können sich allem Anschein nach theilen, da sie öfter zwei Nucleoli enthalten. Dic Einschnürung und Theilung des Kerns habe ich nicht gesehen. Sie wird auch selten sein, denn die Eibildung geht im crwachsenen Thiere nur sehr langsam von statten. Nach innen von diesen Zellen findet man mitunter eine in Zweitheilung begriffene Zelle, welche sich ganz wie bei der oben beschriebenen Zweitheilung des Ei's verhält (b). Nach diesen Kernen - dem Ausfïhrungsgange zu - findet sich eine Lage anderer, welche einen Uebergang zwischen den Strangkernen und dem Keimbläschen darstellt. Der Kern ist nämlich zwar hell und elliptisch, aber enthält eine Menge stäbchenförmige Gebilde, welche wie kleine Theile der Stränge aussehen. Noch weiter vorn hat sich das Protoplasma dem Kerne entsprechend abgegränzt, die Kerne sind wasserhell und das Ei ist fertig.

\section{Saamenbildung (Taf. VI, 8).}

Die Hoden bilden plattenartige Körper, welche netzförmig unter einander zusammenhängen. Sie sind von einer Haut umgeben, auf welcher die jüngsten Zellen aller Wahrscheinlichkeit nach als ein Epithel stehen, wälırend die entwickelteren ebenso wie die fertigen Saamenfäden nach Innen liegen. Dic Entwickelung findet aber an jedem Punkte des Epithels statt, so dafs man durch die Lage gar keinen Anhalt für die Folge der Stadien gewinnt. Da auch die Durehsichtigkeit nicht genügend ist, so bleibt nichts übrig, 
als den Inhalt des Hodens ausfliefsen zu lassen und die verschiedenen Gebilde zu combiniren. Diese Aufgabe wird dadurch erleichtert, dafs der Eierstock die Folge der Entwickelungsstufen deutlich übersehen läfst und man von den Nematoden, deren Ei- und Saamenbildung unter allen Thieren am besten bekannt sein dürfte, weifs, dafs bis zu einem gewissen Punkt die Bildung von Ei und Saamen sich gleicht.

In Wasser und selbst sehr verdünnter Essigsäure ändern sich die verschiedenen Gebilde sehr bedeutend, aber essigsaures Ammoniak, dessen Concentration man nach Bedürfnifs erproben kann, hält sie für längere Zeit ganz unverändert.

Wir finden zunächst die embryonalen Zellen mit granulirten Kernen, welche der reichlichen Saamenbildung entsprechend immer in Theilung getroffen werden. Dann findet man Zellen, deren Kerne in einem Uebergang von den granulirten Kernen zu den Furchungskernen begriffen sind. Sie enthalten nämlich noch einzelne Körnchen, aber vorzugsweise dünne, wellig und unregelmälsig gekrümmte feine Stränge (Fig. 8 e). Weiter finden sich Zellen mit dickeren Strängen, endlich Zellen in der Zweitheilung (Fig. $8 \mathrm{f}, \mathrm{g}, \mathrm{h}$ ). Die Theilung schreitet noch weiter, man findet Zellen in der Viertheilung, welche denselben Character besitzen (Fig. 8 i).

Wie diese Kerne in das folgende Stadium übergehen, konnte ich nicht ermitteln. Die Zellen, aus welchen nun die Bildung der Spermatozoen sich ununterbrochen verfolgen lärst, enthalten meist 10 , mitunter 8 , ziemlich homogene Kerne mit kleinem Nucleolus, auch kleinere Zellen mit einem Kern finden sich. Die Bildung der Spermatozoen geht in der Weise vor sich, wie sie sich immer mehr als gleich für alle fadenförmigen Spermatozoen herausstellt und wie sie z. B. d e la Valette*) dargestellt hat. Statt einer detaillirten Schilderung verweise ich auf die Abbildung.

- Das fertige Spermatozoon ist fadenförmig und kurz vor seinem Vorderende mit mehreren düunen geifselartigen Fäd-

*) XVI, Taf. I, 9. 
chen besetzt. Mesostomum tetragonum hat dieselbe Form der Spermatozoen, sie kommt offenbar noch weiter bei den Plathelminthen vor. Keferstein hat sie von Eurylepta cornuta abgebildet.

\section{System der Plathelminthen und Nenathelminthen.}

\section{Allgemeine Grundsätze.}

Die vorliegenden Untersuchungen werden dazu beitragen, der Ansicht immer mehr Geltung zu verschaffen, dafs die Plathelminthen eine selbstständige Klasse oder einen eignen Typus bilden müssen, wie die Cölenteraten, Nemathelminthen, Arthropoden, Mollusken, Vertebraten u. s. w. Die Eigenschaften, die sie speciell mit den Nemathelminthen gemein haben, kommen überhaupt allen den Typen zu, welche eine höhere Entwickelung erreichen, als die Cölenteraten. Die Unklarheit, welche einige Schriftsteller in der Klasse der Vermes finden, entsteht nur dadurch, dafs man in dieselbe zwei so verschiedene Elemente vereinigt. Trennt man sie aber, so lassen sich die beiden Klassen so gut, wenigstens nicht schlechter systematisch ordnen, wie alle anderen Thierklassen auch. Dafs man bei Thieren, welche keine Zähne, Knochen, Beine, Schaalen besitzen, auf andere Theile seine Aufmerksamkeit richten mufs, namentlich anf die Gewebe, ist klar. Neben der Entwickelungsgeschichte wird die Gewebelehre auch auf anderen Gebieten der Zoologie immer mehr Bedeutung erhalten. Wie die vergleichende Anatomie dadurch geschaffen wurde, dafs man die Anatomie auf die Systematik anwandte, so kann die vergleichende Histologie nur dadurch entstehen, dafs man die Histologie auf die Systematik anwendet. Der Nutzen ist ein gegenseitiger. Nicht blofs die Zoologie kann Gewinn aus der Histologie ziehen, sondern auch die Histologie aus der Zoologie.

Wir wollen im Folgenden das System sowohl der Plathelminthen, als der Nemathelminthen betrachten. Von dieser 
Betrachtung schliefse ich zunächst aus die Rotatoria, da ihre Muskulatur sich weder an die der Nemathelminthen noch der Plathelminthen anschliefst; sie gehören nach meiner Ansicht, die ich bei einer anderen Gelegenheit rechtfertigen werde, zu den Arthropoden, deren eingliedrige Form sie darstellen. Auch die Tunicata und Brachiopoda will ich um die Untersuchung nicht übermälsig zu compliciren unberïcksichtigt lassen. Gelingt es, den Rest gut zu ordnen, so kann man, denke ich, schon zufrieden sein.

Eine besondere Gruppe der Annulata, welche alle segmentirten Thiere der sogenannten Würmer enthält, erkenne ich nicht an. Segmentirung kann in den verschiedensten Typen auftreten, sie ist kein Merkmal eines Typus. Will man die Segmentirung als ein so hervorragends Merkmal betrachten, so mufs man wie $\mathrm{Cuvier}$ die Arthropoden mit den Annulata vereinigen und es ist kein Grund auch die Vertebrata, die ja alle segmentirte Thiere sind, von dieser Gruppe auszuschliefsen. Wenn sich aber nachweisen läfst, dafs ein einzelnes Segment älnlich gebaut ist, einem Einzel - unsegmentirten - Thier, z. B. ein Hirudosegment einer Planaria, ein Lumbricussegment einem Nematoden, so werde ich vorziehen, die ähnlichen Thiere, ob segmentirt, oder nicht, mit einander zu vereinigen. Der Bau eines Hirudo lärst sich mit dem einer Planaria, aber nicht mit dem eines Lumbricus oder eines Nematoden vergleichen. Auch die Entwickelungsgeschichte widerspricht vollkommen der Annahme, alle gegliederten Thiere zu vereinigen. Denn dem gegliederten geht ja auch entwickelungsgeschichtlich ein ungegliederter Zustand voraus, in welchen sich der zoologische Character bereits sehr deutlich ausdrücken kann, z. B. in den mit hinfälligen Borsten versehenen Chätopodenlarven. Ein Typus tritt also in einer einfachen und einer segmentirten Form auf.

Eine weitere Complication eines Typus ist die Bildung einer Geschlechtsform. Die Geschlechtsform bildet sich in der Weise, dafs an einem geschlechtslos bleibenden Thier ein anderes in seiner Form verschiedenes, Geschlechtsproducte bildendes, knospt. So entstehen an den Hydroiden die Medusoiden. 
Mit diesen Geschlechtsformen müssen wir im System alle diejenigen vereinigen, welche zwar nicht durch Knospung entstehen, aber in ihrer Form den Knospen gleichen.

Ein Typus tritt also auf :
1) in einer Stammform,
2) in einer Geschlechtsform.

Beide können wieder einfach oder segmentirt sein.

Die Bildung der Geschlechtsknospen hat man bisher als einen Generationswechsel betrachtet. Die Erscheinungen, welche man unter dem Begriff des Generationswechsels zusamımenfafst, gleichen sich in physiologischer Beziehung dem Resultate nach allerdings, allein in morphologischer Beziehung sind sie so verschieden, dafs es an der Zeit sein dürfte, dieselben vom morphologischen Standpunkte aus zu sondern. Als eine besondere Gruppe von Erscheinungen würde sich empfehlen zunächst zu trennen, denWechsel einer oder mehrerer Fortpflanzungen durch unbefruchtete Eier mit einer Fortpflanzung durch ein befruchtetes Ei. Dieser mit der Parthenogenesis verwandte Vorgang sondert sich wieder in zwei Unterabtheilungen. Die Bildung der ohne Befruchtung sich entwickelnden Eier kann entweder im ausgebildeten Thier vor sich gehen, so bei den Rotatorien, Crustaceen und Aphiden, vielleicht auch bei Gyrodactylus, oder in den Larven bei Trematoden und Dipteren.

Eine zweite Gruppe von Erscheinungen bildet der Procef's der Bildung von Geschlechtsknospen, bei Hydroiden, Nemathelminthen und Plathelminthen. Während bei anderen Knospungsprocessen die Knospe dem Stamme gleicht, ist bei diesem - abgesehen von noch anderen Unterschieden - die Leibeswand der Knospe von der des Stammes in der Anordnung der Muskeln wesentlich verschieden. Die Hydroiden haben nur eine Längsmuskulatur, während die Medusoiden im Peristom eine Quermuskelschicht und in den Scheidewänden und Tentakeln eine Längs- nnd Quermuskulatur besitzen. Dic Unterschiede in der Leibeswand bei Geschlechtsknospen und Stammthieren der Plathelminthen und Nemathelminthen kann ich jetzt wolll als bekannt voraussetzen. Die Knospung geht in allen drei Fällen auf sehr verschiedene Weise vor 
sich. Die Nemathelminthen und Hydroiden zeigen in so weit eine Aehnlichkeit, als das Geschlechtsorgan sich zu einem selbstständigen Individuum hervorbildet. Der Procefs ist bei den Hydroiden zu bekannt, um darauf eingehen zu müssen. Bei den Nemathelminthen, speciell den Nematoden, entsteht der Ausführungsgang der weiblichen Geschlechtsorgane-die Vulva - als eine auf der ventralen Linie liegende Einstülpung der Leibeswand, welche in ihrer vollkommensten Ausbildung eine Quer- und Längsfaserschicht trägt. Bei vielen Nematoden, z. B. den Strongylus und Trichocephalus, hat die Vulva die Eigenthümlichkeit, sich wieder nach Aufsen umzustülpen. Diese Umstülpung erfolgt vollständig bei Sphärularia*), und zwar gleichzeitig mit dem Eintritt einer Darmschlinge in den hervorgetretenen Sack. Während nun in diesem Falle die Geschlechtsknospe an dem Mutterthier haften bleibt, wird sie in einem andern Falle bei Phoronis zu einem selbstständigen Thier. Der Leibesschlauch der Geschlechtsknospe bildet sich an der Actinotrocha genannten Phoronislarve wie eine Vulva und hat auch später dieselben Schichten der Muskeln wie eine Nęmatodenvulva. Indem dieser Schlauch sich hervorstülpt, schwindet durch Contraction und Resorption die Leibeswand der Actinotrocha bis auf den Tentakelkranz und dem Boden desselben, welche den Schlul's des Schlauches am Vorderende bewirken.

*) Es ist mir leider bisher noch nicht gelungen ïberwinternde Hummeln während der Monate October und November zu finden. Es würde von grölster Wichtigkeit sein die Entstehung der Umstülpung und die Gestalt der gewils vorhandenen Männchen zu beobachten. Die Umstülpung selbst kann aber kaum in Zweifel gezogen werden, wenn man bedenkt, dafs die Embryonen von Sphärularia sich in Nichts von gewöhnlichen Nematodenembryonen unterscheiden. Wer das Glück hat Hummeln zu dieser Zeit zu. finden, möge die Gelegenheit nicht versäumen. Vielleicht findet sich eine gelehrte Gesellschaft, welche die Entwickelung der Sphärularia zum Gegenstand einer Preisaufgabe macht. 
Ich habe seiner Zeit die Vermuthung ausgesprochen, dafs anch noch eine zweite Art der Geschlechtsknospenbildung bei Nemathelminthen existiren möge, welche darin besteht, dafs der Mastdarm sich ausstülpt und zum Leibessehlauch wird. Ferner, dafs der aus Mitraria hervorgehende Wurm sich vielleicht in dieser Art bilden würde. Mets chnik off*) hat dem aber bestimmt widersprochen. Wenn nun auch der Umstand in's Gewicht fällt, dafs er eine grölsere Anzahl von Exemplaren in verschiedeneren Stadien beobachtet hat, so möchte ich doch, dafs diejenigen, welche diese seltene Larve zu Gesicht bekommen, ihre Aufmerksamkeit nochmals darauf richten. Es geht aus Metschnik off's Abbildung hervor, dafs die Entwickelung des Wurmes sehr erheblich von der gewöhnlichen Bildung eines Chätopoden abweicht, indem der Leib der Larve als eine Einstulpung der Haut angelegt wird und dann weiter vor wäehst. Es bleibt also immer noch die Möglichkeit, dafs hier ein Knospungsprocefs vorliegt, wenn auch in etwas anderer $W$ eise als ich vermuthete. Wenn meine Abbildung des Wurmes von der Metschnikoff's abweicht, so kann dies nur an einer Verschiedenheit der Species liegen. Ich habe dieselbe wenn auch nur in den Umrisscn doch mit aller denkbaren Treue entworfen.

Bei den Plathelminthen läist sich schwerer sagen, ob der durch Knospung sich bildende Leibesschlauch irgend einem Organ der Stammform entspricht. Die Cestodenblasen stehen entweder auf einer sehr tiefen Organisationsstufe, oder sind in ihrem Bau noch zu wenig gekannt, als dafs man sie mit den uns bekannten Stammformen dieser Klasse vergleichen könnte. Eher wäre dies bei Pilidium möglich. Ich selbst habe mich längere Zeit mit der Entwickelung von Pilidium beschäftigt und möchte, obgleich ich mit meinen Untersuchungen nicht zum Abschlufs gelangt bin, auf einen bisher übersehenen Punkt aufmerksam machen. Nach der Darstellung vou Joh. Müller, Busch sowie von Pagenstecher und L e a kart soll der Nemertes innerhalb der Leibeshaut 
des Pilidiun entstehen und dann sich losreifsen. Der Vorgang schien mir aber vielmehr in der durch nebenstehende Figur schematisch dargestellten Weise stattzufinden, dal's sich um den Mund eine ringförmige Tasche

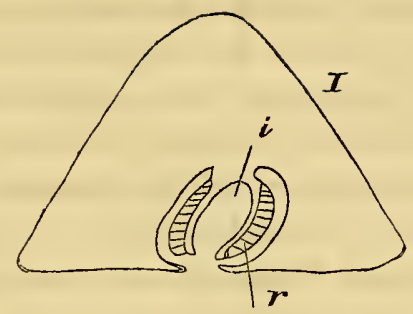
der Leibeswand bildet, aus deren Grund die neu sich bildende Leibeswand sammt dem Darmkanal hervorragt, so dafs schliefslich der $\mathrm{Ne}$ mertes nur durch eine Art Nabel mit dem Pilidium zusammenhängt. Denkt man sich den Darmkanal zuerst

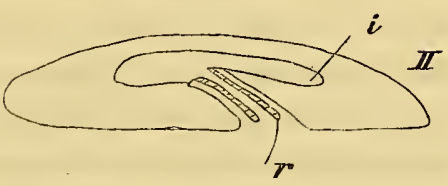

I schematisclier Durchschnitt eines, II Pilidium einer Planaria, i Darmkanal, $\mathrm{r}$ in I Leibeswand des jungen Nemertes, in II Mundrüssel.

nach innen von dem muskulös en Rohr, der neuen Leibeswand, gelegen, so würde die Lage des Rohrs an den des Rüssel's der Planarien erinnern. Die Knospung würde so zu verstehen sein, dafs ein rüsselartiges Organ den Darmkanal sammt Nervensystem umwächst und dann selbstständig wird. Dafs dieser Nabel existirt, ist unzweifelhaft, man kann auch die Tasche auf dem optischen Querschnitt deutlich erkennen. Nur ist es mir nicht möglich gewesen, den Eingang der Tasche zu unterscheiden. Beim Losreifsen des Wurmes sieht man aber deutlich den Wurm aus der Tasche herausschlüpfen. Jene Tasche des Pilidium zeigt uns auch eine grofse Aehnlichkeit zwischen der Knospung der Nemertinen und Cestoden.

\section{System der Plathelminthen.}

$\mathrm{Zu}$ weit in die Details einzngehen war für vorliegenden Zweck nicht nöthig, da die Begränzung der von den meisten Schriftstellern anerkannten kleineren Gruppen nicht wesentlich verändert worden ist.

Einer Rechtfertigung bedarf es, dafs die Poliadeen zu den segmentirten Formen gerechnet worden sind. Aeufserlich 
drückt sich die Segmentirung allerdings kaum aus, nur vielleicht darin, dafs die Poliadeen die Neigung haben in Stücke zu zerbrechen,. deren Bruchfläche auffallend glatt ist. Ganglienknoten besitzen sie nicht, der Ganglienbelag ist gleichmälsig über die Längsstränge vertheilt, wie dies bei gegliederten Nemathelminthen (Lumbricus) bekanntlich auch vorkommt. Dagegen sind die Queräste der Hauptnervenstämme so regelmälsig vertheilt, dals sie eine Segmentirung andeuten. Malacobdella, welches ebenfalls keine Ganglienknoten besitzt, bildet in dieser Beziehung einen Uebergang zwischen den Poliadeen und Hirudineen. Die Sagittalmuskeln sind gruppenweise angeordnet derart, dals man darin eine allerdings niedere Stufe der Segmentirung erkennen kann. Auch Nemertes kann man vielleicht zu den segmentirten Formen rechnen.

$\mathrm{Ob}$ die Zusammenstellung von Bipalium und Dinophilus haltbar ist, mag die Zukunft lehren. Der Bau von Bipalium mufs erst genauer bekannt sein. Sicher freilich ist die Stellung von Bipalium in der Nähe der Rhabdocölen.

Die übrigen systematischen Aufstellungen sind in den vorhergehenden Untersuchungen wiederholt begründet worden.

\section{Stammform.}

Muskelhaut aus Ring- Diagonal- Längs- und Sagittalfasern zusammengesetzt. Längsfaserschicht ohne Unterbrechung, Excretionssystem verzweigt, an einzelnen Stellen bewimpert.

A. einfache Form :

hermaphroditisch keine Blutgefäfse, Hauptnervenstämme seitlich.

a., Epithel vergänglich.

Trematoda.

b., Epithel bleibend und wimpernd.

Planaridea.

B. segmentirte Form :

Blutgefälse vorhanden.

a., Rüssel in den Mund sich öffnend, mit Kalkstilet 
bewaffnet, Nervensystem mit zwei seitlichen Hauptstämmen, Haut mit Wimperepithel.

Poliadea (Polia Borlasia).

b., Saugscheibe am Hinterende.

1., Nervensystem mit zwei seitlichen Hauptstämmen.

Malacobdella.

2., Nervensystem mit einem ventralen Hauptstamm. Hirudinea.

c., Segmente mit Füisen.

Onychophora.

\section{Generationsform.}

Muskelhaut aus einer äul'seren dünnen Querlängsschicht, inneren Längs-, Ring- und Sagittalfasern zusammengesetzt. Hauptnervenstämme seitlich.

A. Epithel vergänglich, kein Darm, keine Blutgefäfse.

Hermaphroditen.

Cestoidea.

a., unsegmentirt.

Caryophyllaeus, Amphiptyches (?).

b., segmentirt.

1., Kopf abgerundet ohne Auszeichnung :

Ligula.

2., Kopf mit Sauggruben.

aa., ohne Rüssel :

Dibothrium, Triaenophorus, Solenophorus,

Tetrabothrium.

bb., mit vier Rüsseln :

Tetrarhynchus.

3., Kopf mit Saugnäpfen :

Taenia.

B. Epithel bleibend.

a., kein Rüssel, Excretionssystem vorhanden :

Rhabdocöla.

b., ein von der Rückseite der Mundhöhle entspringender kurzer Rüssel : 
Bipalium(Sphyrocephalus Schmarda).

Dinophilus.

e., ein auf der Mitte des Kopfes hervorstreckbarer Rüssel ohne Stilet.

1., keine Kopfspalten.

aa., Excretionssystem vorhanden, keine Blutgefäfse. Prostomea.

bb., Excretionssystem fehlt. Blutgefäfse vorhanden : Cephalothrix.

2., Kopfspalten vorhanden, kein Excretionssystem. aa., Blutgefäfse fehlen : Stenostomm. bb., BlutgefäIse vorhanden : Nemertes.

\section{System der Nemathelminthen.}

Wenn wir die zwei Typen der Nemathelminthen und Plathelminthen unterscheiden, so soll damit nicht gesagt sein, dafs diese Trennung unabänderlich bestehen müsse. Bis jetzt aber ist eine Uebergangsform zwischen Plathelminthen und Nemathelminthen unbekannt. Wenn Rathke seinen Ramphogordius den Nemertinen verwandt hielt, so läfst sich dies aus der damaligen Unkenntnifs erklären, Rhamphogordius ist nach dem jetzigen Standpunkt ein echter Nemathelminth. Es existirt aber eine 'Thiergruppe, welche man leicht als einen solchen Uebergang betrachten könnte, nämlich die Gastrotricha (Metschnik off), Chätonotus und Ichthydium. Sie sind neuerdings von Metse h n ik off*) wieder zu den Rotatorien gezogen worden, wohin sie bereits Ehrenberg gestellt hatte. Nach den Bewegungen zu urtheilen, besitzen diese Thiere Muskeln. Jeder Zweifel über ihre systematische Stellung würde gehoben sein, wenn es gelänge, die Anordnung dieser Muskeln zu erkennen. Ehe aber unsere Mikroskope verbessert oder ehe sich gröl'sere Species finden, wird dies nicht möglich sein.

Durch die Unterscheidung der Stamm- und Generationsform glaube ich das System gegen früher wesentlich verbessert zu haben. Selbst solche Charactere, welche nur in der

*) XXI. 
Muskulatur liegen, traten sonst nicht deutlich hervor. Jetzt kommt z. B. die äufsere Quermuskulatur unter der Stammform nur den segmentirten Formen zu, während bei der Generationsform allen, auch den einfachen. Blutgefälse treten in der Stammform nur bei den segmentirten auf, in der Generationsform auch bei einfachen. Um Mifsverständnisse zu verhüten, will ich bemerken, dafs man in der Generationsform der Nemathelminthen bis jetzt nur einfache (keine segementirten) kennt.

Unter den Bryozoen sind Formen vorhanden, welche offenbar sehr tief stehen und uns die änfserste Reduction der Muskeln zeigen. Ich meine Loxosoma, welches nur einen vorderen Ringmuskel und hinteren Längsmuskel im Stiel besitzt. Denkt man sich diese Muskeln aber zu Schichten ausgebreitet, so kommt doch die typische Muskulatur zu Stande. Eine andere Reduction der Muskeln zeigen die Formen, welche ein verkalktes Zoöcium besitzen. Die typische Muskulatur ist bei ihnen nur an dem beweglichen Theil - der Tentakelscheide - entwickelt. Soweit die Leibeswand fest ist, fehlt die Ringmuskulatur ganz und die Längsmuskeln stehen frei im Leibesraum, vom Boden nach dem unverkalkten oberen Theil des Zoöcium sich erstreckend, z. B. bei Membranipora. Wenn man die Muskeln einer Schildkröte mit der eines anderen Wirbelthieres vergleicht, wird man eine ähnliche Veränderung der Muskulatur bemerken, welche offenbar mit der Erhärtung der Haut zusammenhängt.

Von den Nematoidea habe ich die Gordiacea getrennt, um in die Characteristik der Nematoideen die Seitenfelder und Medianlinien aufnehmen zu können. Die Seitenfelder sind bei einigen Nematoideen allerdings wenig entwickelt, so dafs ich sie bei Trichocephalus früher ganz geleugnet habe. Indel's habe ich mich jetzt überzeugt, dal's die Seitenfelder wenigstens am Schwanztheil der Männchen vorhanden sind und besonders dadurch deutlich werden, dafs die ventralen Quermuskeln sich daran setzen.

$\mathrm{Ob}$ sich bei den Gordius ventrale Quermuskeln finden, bin ich schwankend geworden. In der Monographie der $\mathrm{Ne}$ - 
matoden habe ich solche abgebildet, es ist mir aber in neuster Zeit nicht gelungen, dieselben wieder zu finden, auch nicht am Schwanzende des M̈̈nnchens, überhaupt keine Andeutung der Seitenfelder und Medianlinien.

\section{Stammform (Lobocephala).}

Muskelhaut aus Längsfasern bestehend. An jedem Ende des Körpers eine Oeffnung, dorsale und ventrale Seite verschieden. Excretionsgefälse wenn vorhanden unverästelt aus zwei seitlichen Hauptstämmen bestehend.

A. einfache Form. Hauptstämme des Nervensystems dorsal und ventral gelegen, keine Blutgefälse.

a., nur eine dorsale Medianlinie, vorhanden : Gordiacea (Gordius).

b., dorsale und ventrale Medianlinien und Seitenfelder vorhanden. Innere Quermuskeln auf der ventralen Seite an beschränkten Stellen.

1., Mund ohne Kiefer :

Nematoidea.

2., Mund mit Kiefern :

Chätognatha.

B. segmentirte Form.

Seitenfelder, Bauch und Rückenlinie. Innere Quermuskeln von der Bauchlinie zum Seitenfeld. Hauptstamm des Nervensystems ventral. Blutgefälse kommen vor.

a., Keine Borsten, äufsere Quermuskeln fehlen : Gymnotoma (Polygordius).

b., Borstenbündel, äufsere Quermuskeln vorhanden : Chätopoda.

II. Generationsform (Rhynchocephala).

Muskelhaut aus äufseren Quer- und inneren Längsfasern bestehend, keine Medianlinien, keine Seitenfelder. Blutgefälse kommen vor.

A. Darmkanal hufeisenförmig, Mund und After genähert. 
a., Vermehrung durch Knospung:

Bryozoa.

b., keine Knospung

Sipunculidea.

B. Darmkanal gestreckt,

a., ohne Mund und After :

A canthocephala.

b., mit Mund und After :

Priapulus, Halicryptus, Bonellia, Echiurus, Sternaspis.

\section{Beschreibung einiger seltener Species.}

1. Prorhynchas stagnalis (M. Schulze) [Taf. VII, Fig. 1-5).

Diese Species habe ich nicht selbst beobachtet. Mein verehrter Freund Herr N. Li eberkühn hat sich aber vor einer Reihe von Jahren sehr eingehend danit beschäftigt und mir die von R. G. W a g en er gezeichnete Tafel freundlichst zur Veröffentlichung überlassen. Sie enthält einige sehr wichtige Beobachtungen. Max. Schulze*) beschreibt einen, mit Stacheln versehenen Rüssel, welcher am Vorderende nach aufsen gestreckt werden kann und nach innen mit einer. Blase in Verbindung steht. Nach M. Schulze soll diese Blase eine Giftdrüse sein.

Offenbar hatte M. Schulze keine geschlechtsreifen Thiere vor sich, denn dann zeigt sich, dafs die Blase eine Saamenblase und das ganze Organ ein Penis ist.

In den Penis münden viele einzellige Drüsen. Auch auf der ganzen Haut zerstreut (Fig. 5) öffnen sich Drüsen. Dafs die Jungen das Ei in definitiver Gestalt verlassen, ist aus Fig. 4 ersichtlich.

Die systematische Stellung von Prorhynchus lä/st sich schwer angeben. Die Grübchen am Kopf erinnern an die Poliadeen. Aber der Rüssel ist verschieden von dem der Poliadeen, wie auch von dem der Nemertes Auch

*) IX, S. 60 . 
hier würde die Kenntnifs der Muskulatur leicht Aufschlufs geben.

2. Mesostomum obtusum (M. Schulze) (Taf. IV, Fig. 1).

Das Thier wurde von mir bei Giefsen in einem kleinen Weiher (auf dem Schiffenberg) während des Octobers im geschlechtsreifen Zustand häufig beobachtet. Da die Abbildung M. Schulze's *) wie es scheint nach einem unentwickelten Thier gemacht ist, habe ich nun eine mehr detaillirte gegeben. Die Zeichnung wird auch ohne nähere Beschreibung verständlich sein. Die Thiere hatten immer nur ein hartschaaliges, mit einem dünnen Stiel versehenes $\mathrm{Ei}$ bei sich. Als Eigenthïmlichkeit will ich hervorheben, dafs der Körper bis zu der in der Figur angegebenen ovalen Linie im Hinterende von einer geilblichen blutartigen Flüssigkeit erfüllt war. Die Netze im Schwanz sind mit Körnchen, welche lebhafte Molekularbewegung besitzen, erfüllt und haben offenbar dieselbe Bedeutung, wie die der Spinndrüsen von M.Ehrenbergii.

3. Stenostomum leucops (O. Schmidt**). (Taf. IV, Fig. 2).

Ich habe dieses hier, und wie ich mich erinnere auch in Berlin sehr häufig vorkommende Thier vom März bis October wiederholt, allein niemals geschlechtsreif gesehen. Zwar findet man darin, und zwar nicht im März wohl aber im October einen Haufen Zellen, welche einen sehr grofsen Kern und zahlreiche stark lichtbrechende Körner enthalten und welche man mit M. S chulze***) geneigt sein kann für ein weibliches Geschlechtsorgan zu halten. allein eine weitere Entwickelung desselben habe ich nicht beobachtet. Ebensowenig gelang es mir, männliche Geschlechtsorgane zu finden. Die Muskulatur der Leibeswand muls äufserst gering entwickelt sein, ich habe sie nicht sehen können, aus den lebhaften Contractionen geht jedoch ihre Existenz wohl hervor. Das Thier ist

*) IV, Taf. V, Fig. 1.

**) XXXIII, S. 59.

***) XXXIV, S. 286. 
so zart, dafs es weder Reagentien noch auch einen selbst gelinden Druck verträgt. In der Haut liegen zahlreiche, sehr dünne, in Essigsäure lösliche Stäbchen. Der Mund führt durch einen engen Oesophagus in den Darm, welcher aus wimpernden Zellen besteht. Der Darm ist braun im auffallenden Licht, wenn auch, wie mir schien, nicht so entschieden, als $\mathrm{O}$. Schmidt abbildete. Im Kopf liegt ein deutliches Nervensystem. Es besteht aus zwei seitlichen Ganglien, welche sich dorsal und ventral durch Brücken von Fasern verbinden. An beiden Seiten des Kopfes liegen zwei tiefe Höhlen oder Spalten, welche mit ihrem hinteren Ende die Ganglien berühren. Mit den Ganglien ist ferner und zwar nach rückwärts durch einen kurzen Fortsatz jederseits eine Kugel verbunden, welche auf der Innenseite ihrer Fläche mit kleineren hellen Kugeln besetzt ist. Ein Pigment fehlt diesen Sinnesorganen immer.

Durch den Ring des Nervensystems geht ein Kanal, welcher vom Vorderende bis zum Hinterende auf der Rückenseite verläuft. Dieser Kanal ist von $\mathrm{O}$. Schmidt für ein Wassergefäfs gehalten worden. Seine Meinung kann ich nicht theilen. Der Kanal hat mit keinem bekannten Wassergefäls irgend eines Plathelminthen Aehnlichkeit. Er ist unpaar; hat keine Wimperbüschel, überhaupt keine Wimperu, er ist unverästelt und geht durch den Ring des Centralnervensystems. Alle diese Eigenschaften unterscheiden ihn von dem Wassergefälse der Plathelminthen. Dagegen hater eine auffallende Aehnlichkeit mit der Rüsselscheide der $\mathrm{Ne}$ mertinen. Bei starker Vergrölserung sieht man auch einen Streifen am Vorderende in der Mitte des Kanals verlaufen, welcher weiter hinten mit der Wand des Kanals verschmilzt, er dürfte wohl als Rüssel zu betrachten sein, freilich wohl nur als Rudiment eines solchen. Denn hervorgestreckt habe ich ihn nie gesehen. Auch das dürfte wohl zu Gunsten dieser Deutung sprechen, dafs man den Kanal in sehr verschiedener Weite und häufig gekrümmt findet, also aller Wahrscheinlichkeit nach seine Wand aus Muskelfasern zusammengesetzt ist. 
Nicht abgebildet habe ich dunkle Körnerhaufen ungewisser Bedeutung, welche in grolser Anzahl durch den Körper zerstreut sind.

Nach dieser Beschreibung darf man Stenostomum leucops wohl vollständig mit den Nemertinen vereinigen, ebenso St. unicolor (Schmidt), welches offenbar St. leucops sehr gleicht und vielleicht auch Schizostomum productum, an dessen Vorderende O. Schmidt einen hellen Raum abbildet, der an den Rüssel von Stenostomum erinnert. Dagegen ist Microstomum lineare, von welchen wir eine sehr genaue Beschreibung M.Schulze's *) besitzen, offenbar von Stenostomum sehr verschieden. Bei M. lineare konnte M. Schulze kein sogenanntes Wassergefälssystem (Rüsselscheide) und kein Nervensystem finden, welches bei Stenostomum doch kaum zu übersehen ist. Trotz der Grübchen am Kopf, die aber auch viel kleiner sind als die Kopfspalte von Stenostomum, scheint mir Microstomum lineare zu den rüssellosen Rhabdocölen, etwa zu Macrostomum - mit dem es auch in der Gestalt des Penis übereinstimmt gestellt werden zu müssen. Beide gleichen sich allerdings in der Quertheilung, dieselbe findet sich aber noch bei anderen Rhabdocölen, z. B. Derostomum Catenula D u g e s, sie kann also kaum zur Begründung einer systematischen Verwandtschaft gebraucht werden. Der After von Stenostomum ist eine sehr wenig ausgebildete Oeffnung, die möglicherweise nur von der Quertheilung herrührt.

*) XXXIV. 


\section{Litteratur.}

I. Z eller, Untersuchungen über die Entwickelung des Diplozoon paradoxum, v. Siebold und Kölliker. Zeitschr. f. w. Z. XXII, S. 168. 1872.

II. v. Will moes-S uhm, zur Naturgeschichte des Polystomum integerrimum und P. ocellatum, v. S i e bold und Kölliker. Zeitschr. f. w. Z. XXII, S. 27.

III. Leydig, zur Anatomie von Piscicola geometrica mit theilweiser Vergleichung einheimischer Hirudineen, v. Siebold und Kölliker. Zeitschr. f. w. Z. I, S. 103 (1849).

IV. M. Schulze, Beiträge zur Naturgeschichte der Turbellarien. Greifswald 1851.

V. Leuckart, Mesostomum Ehrenbergii anatomisch dargestellt. Troschel's Archiv f. Naturgeschichte XVIII, S. 234 (1852).

VI. Stieda, ein Beitrag zur Anatomie des Bothriocephalus latus, Reichert und Dübois. Archiv 1864, S. 174.

VII. Sommer und Landois, über den Bau der geschlechtsreifen Gìlieder von Bothriocephalus latus, v. Siebold und Kölliker, Zeitschr. Bd. XXII (1872), S. 40.

VIII. W a gener, G. R., Entwickelung der Muskelfasern. Schriften der Gesellschaft zur Beförderung der gesammten Naturwissenschaften zu Marburg. Supplementheft IV. Marburg und Leipzig 1869. Sitzungsberichte der Gesellschaft zur Beförderung der gesammten Naturwissenschaften zu Marburg 1872. November.

IX. Eckhardt, C., Entwickelungsgeschichte der Herzmuskulatur von Henle und $\mathrm{P}$ fe ufer, Zeitschr. f. rationelle Medicin 3. R. Bd. XXIX, S. 55. (1869). 
X. Schneider, Monographie der Nematoden. Berlin 1866.

XI. W alter, G., Beiträge zur Anatomie einzelner Trematoden, Troschel's Archiv für Naturgeschichte 1858 , S. 269.

XII. Leuckart, R., die menschlichen Parasiten I, 1. Bd. 1863.

XIII. Blumberg, über den Bau des Amphistoma conicum, Dorpat 1871.

XIV. Schmidt, O., die dendrocölen Strudelwürmer aus der Umgebung von Gratz, Siebold und Kölliker. Zeitschr. X, S. 24 (1859).

$X V$. Keferstein, Untersuchungen über niedere Seethiere, v. Siebold und Kölliker, Zeitschr. XlI, S. 1 (1862).

XVI. Derselbe, Beitrag zur Anatomie und Entwickelung der Seeplanarien. Abhandlungen der Gesellsehaft der Wissenschaften zu Göttingen XIV (1868).

XVII. Schmidt, O., Untersuchungen über Turbellarien von Corfu und Cephalonia, v. Siebold und Kölliker, Zeitschr. XI, S. 1 (1861).

XVIII. Derselbe, die rhabdocölen Strudelwürmer aus den Umgebungen von Krakau, Denkschriften der Wiener Akademie XV, 2. Abtl. S. 20.

XIX. v. Siebold, über undulirende Membranen, v. Si ebold und Kölliker, Zeitschr. f.w. Z. II, S. 356.

XX. Thiry, Beiträge zur Kenntnifs der Cercaria macroceria, v. Siebold und Kölliker, Zeitschr. f. w. Z. X, 271 (1859).

XXI. Leydig, Lehrbuch der Histologie des Menschen und der Thiere. Frankfurt 1857.

XXII. Wagener, G. R., Beiträge zur Entwickelungsgeschichte der Eingeweidewürmer. Haarlem 1857.

XXIII. van Beneden, Edouard, Recherches sur la composition et la signification de l'oeuf. Mémoires couronnés par l'Academie royale de Belgique, tome XXXIV, 1868. Bruxelles 1870. 
XXIV. Grube, über den Bau von Peripatus Edwardsii,

M ïller's Archiv f. Anatomie 185̄3, S. 322.

XXV. Blanclıard, Mémoire sur un animal du genre Malacobdella. Annales $d$. sciences naturelles, serie I, tome III (1845), Zoologie S. 364.

XXVI. Quatrefages, Mémoire sur les Nemertiens. Annales de sciences naturelles, serie III, tome VI, Zoologie 1846, S. 173.

XXVII. Metschnik of $f$, E., über die Metamorphose einiger Seethiere, v. Siebold und Kölliker, Zeitschrift f. w. Z. Bd. XXI, S. 233.

XXVIII. Schneider, A., zur Entwickelungsgeschichte der Bryozoen und Gephyreen, M. Schulze, Archiv f. mikrosk. Anatomie 13d. V, S. 230 (1869).

XXIX. Nitsche, H., Untersuchungen über den Bau der Taenien, v. Siebold und Kölliker, Zeitschr.f. w. Z. XXIII, S. 181 (1873).

XXX. v. la Valette, St. George, der Hoden, in Strick er's Handbuch der Gewebelehre, Bd. I, S. 522.

XXXI. Metschnik off, E., über einige wenig bekannte Thierformen, v. Siebold und Kölliker, Zeitschrift für wissenschaftliche Zoologie Bd. XV, S. 450 (1865).

XXXII. Focke, Planaria Ehrenbergii, Annalen d. Wiener Museum Bd. I, S. 191 (1836).

XXXIII. Schmidt, O., die rhabdölen Strudelwürmer des süfsen Wassers. 1848.

XXXIV. Schulze, M., über die Microstomeen, eine Familie d. Turbellarien, Troschel's Archiv Bd. XV, S. 286 (1849).

\section{Erklärung der Abbildungen.}

Taf. III. betrifft nur Mesostomum Ehrenbergii.

Fig. 1. Uebersicht der Anatomie.

Die paarigen Organe sind meist nur auf einer Seite gezeichnet. 
b. Dotterstöcke.

c. Uterus.

d. Hoden.

e. Ausführungsgang desselben.

f. Penis.

g. Blase, in welche wahrscheinlich die Dotterstöcke münden.

h. Bezeichnung für den Eierstock ist vergessen worden.

i. Speichelzellen und Ausführungsgänge derselben.

k. Drüsen, welche in die Penisscheide münden.

1. Spinndrüsen und ihre verästelten Gänge.

m. Vordere oder obere Hirncommissur.

n. Untere oder hintere Hirncommissur.

o. Zellen mit den grofsen Stäbchen.

p. Umrifs des vorderen Theil des Darmes.

Fig. 2. Uebersicht der Muskulatur.

Fig. 3. Querschnitt, die Rückseite nach unten.

s. Sagittal- und Ringfasern.

1. Längsfasern der Hautschicht.

d. Darmkanal.

Fig. 4. Isolirte Sagittalfaser.

Fig. 5. Verschiedene F'ormen von Stäbchen und Secreten nach der natürlichen Entladung auf einem Objectglas $500 \%$.

a. Grofse und mittlere Stäbchen.

b. Kleinere Stäbchen.

d. Wahrscheinlich die kleinsten Stäbchen.

c. Körper aus den Epithelzellen.

Fig. 6. Wassergefäls. Ein Stamm von gröfster Weite mit Wimperreihen, von vorn und von der Seite gesehen. Ein Stamm von kleinster Weite mit den Endbechern.

$$
\text { Taf. IV. }
$$

Fig. 1. Mesostomum obtusum (Länge 7,ூ $\mathrm{mm}$ ).

a. Eierstock.

b. Dotterstock. 


\section{d. Hoden.}

f. Penis.

m. Vordere Hirncommissur.

o. Stäbchenzellen. Man sieht hier sehr deutlich über und unter dem Nerven einen Strang, der Ausläufer der Stäbchenzellen, nach der Kopfspitze gehen.

Fig. 2. Stenostomum leucops (Länge $2 \mathrm{~mm}$ ).
a. Mund.
b. Darm.
c. Rüsselscheide.
c'. Rüssel.
d. Nervensystem.
e. Kopfspalte.
f. Sinnesorgan.

Taf. $V$ (betrifft mit Ausnahme von Fig. 7 Mesostomum Ehrenbergii).

Fig. 1 a. Epithelzellen, Flächenansicht. Die eine Zelle mit Secretkörpern erfüllt.

1 b. Seitliche Ansicht der Epithelzellen mit Secretkörpern, Stäbchen und dem Kern.

Fig. 2 a. Speichelzellen nach links wie Ausläufer mit Secret gefüllt.

2 b. Spinndrüsenzelle mit den stäbchenförmigen Körpern.

Fig. 3 a. Stäbchenzelle für die kleinsten Stäbchen, ihre Ausläufer und Endanschwellungen mit dem hellen Fleck.

3 b. Stäbchenzelle für die grofsen Stäbchen mit Ausläufer. Die Kugeln sind die Anlagen der Stäbchen.

Fig. 4. Eierstock.

a. Granulirte Kerne.

b. Kerne in der Zweitheilung mit dem Character der Furchungskugelkerne.

c. Kern noch mit Stäbchen den Resten der strangförmigen Kerne erfüllt.

d. Fertige Eier mit homogenen Keimbläschen mit Körnern gefüllt, zur Zeit der Winterbrut. 
Weiter ist der Eierstock mit Längs- und Quermuskeln versehen.

Fig. 5. Furchungsprocels.

a. Sommerei mit Membran, Dotterzellen, Spermatozoen, der Keimfleck unverändert. $250 / 1$.

b. Erste Furchungskugel in der Vorbereitung zur Zweitheilung. Kern strangförmig, äquatoriale Ansicht. Die polare Anordnung der feinen Körner im $\mathrm{Ei}$ ist durch den Lithographen zu undeutlich ausgedrückt.

c. Dieselbe polare Ansicht.

d. u. e. Weitere Stadien der Zweitheilung.

f. Embryonale Zelle mit granulirtem Kern.

$\mathrm{b}-\mathrm{f}$ sind nach Anwendung verdünnter Essigsäure gezeichnet. Fig. 6. Ei weiter fortgeschritten, als 5 a. Die Dotterzellen mit den nach innen liegenden Vacuolen und zwei Furchungskugeln sind sichtbar. ${ }^{250 / 1}$.

Fig. 7. Distoma cygnoides, um die Aehnlichkeit des Furchungsprocesses mit M. Ehrenbergii zu zeigen.

Fig. 8. Bildung des Saamens.

a., b., c., d. Verschiedene Formen und Stadien der Zellen mit granulirtem Kern.

e. Zelle mit beginnender Strangbildung im Kern.

f. Weiteres Stadium derselben.

g., h. Zweitheilung derselben.

i. Viertheilung derselben.

k. Einzelne Zelle, wahrscheinlich Uebergang des stranghaltige Kernes in den Kern der Bildungszellen des Spermatozoon.

l. u. m. Bildungszellen der Spermatozoen.

$\mathrm{n}-\mathrm{v}$. Bildung der Spermatozoen aus einer einzelnen Zelle.

Fig. 9. Fertiges Spermatozoon.

Fig. 10. Blindes Ende eines Dotterstocksfollikel, während der Bildung des dunklen Dotters. 
Fig. 11. Zellen, welche mit dem Faden am Darm sitzen, mit granulirtem Kern und dem Furchungskugelkern in der Zweitheilung.

\section{Faf. VI.}

Fig. 1. Nemertes (spec.?), seitliches Stück des Körpers, stark vergrölsert.

a. Epithel mit Stäbchen.

$b^{\prime}$. Längsmuskeln der Haut. Zwischen a und $b^{\prime}$ Quermuskeln.

b. Parenchymzone mit der Bildungsstätte der Stäbchen.

c. Faserige Bindegewebsschicht.

d. Längsmuskeln.

e. Quermuskeln.

f. Längsmuskeln in Primitivbündeln.

g. u. h. Protoplasma mit einzelnen Längsfasern.

i. Epithel des Darmes.

k. Nervenstamm mit den seitlichen Ganglienzellen.

Fig. 2. Derselbe, ganzer Querschnitt, schwächere Vergröfserung. Bedeutung der Buchstaben wie in 1.

Fig. 3. Polia (spec.?), Querschnitt.
a. Nervenstamm.
b. Aeufseres Epithel.
c. Basementmembran.
d. Quer- und Diagonalschicht.
e. Längsfaserschicht.
f. Darmkanal.
g. Rüssel in der Rüsselscheide.

Fig. 4. Flächenansicht der Muskulatur einer Sülswasserplanarie, nachdem das Epithel und die Zelle des mittleren Blattes abgelöst sind.

Fig. 5. Oesophagus (Mundsaugnapf) von Mesostomum Ehrenbergii. 
Taf. VII, Fig. 1-5, Prorhynchus stagnalis (gezeichnet von G. R. W agen er).

Fig. 1. Totalansicht.

Fig. 2. Penis mit Saamenblase und die einmündenden Drüsen.

Fig. 3. Bildung der Spermatozoen.

Fig. 4. Eier in verschiedenen Stadien, b. Embryo.

Fig. 5. Stück der Haut, um die Hautdrüsen zu zeigen.

Fig. 6. Querschnitt einer Sülswasserplanarie.

a. Epithel mit Stäbchen.

b. Quer- und Diagonalfasernschicht.

c. Längsfasernschicht.

d. Sagittalfasern.

f. Stäbchen an ihrer Bildungsstätte.

e., g., h. Verschiedene Zellformen des Protoplasma.

i. Dotterstock.

k. Darmkanal.

Fig. 7 a. Halber Querschnitt von Bipalium, schwache Vergrölserung, h. Darmkanal g. Kanal ungewisser Bedeutung. Die übrigen Buchstaben wie in $7 \mathrm{~b}$.

7 b. Stück des Querschnitts, stärker vergröfsert.

a. Epithel.

b. Längsmuskeln der Haut.

f. Stäbchenzellen in der Parenchymzone.

d. Längsmuskeln.

e. Sagittalmuskeln.

Fig. 8. Tristoma hamatum.

8 a. Querschnittt.

a. Haut.

b. Quer- und Diagonalfasern.

c. Längsfasern.

d. Sagittalfasern.

e. Zellen des Protoplasma.

8 b. Isolirte Sagittalfaser mit dem umhüllenden Protoplasma und Kern. 


\section{Inhaltsverzeichnils.}

1. Epithel . . . . . . . . . . . 1

2. Das mittere Blatt . . . . . . . . 3

Muskeln . . . . . . . . . . . 4

Drüsengewebe . . . . . . . . . . . 13

Stäbchen . . . . . . . . . . . 14

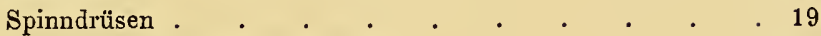

Drüsen der Geschlechtsorgane . . . . . . 22

Speicheldrüsen . . . . . . . . . . 23

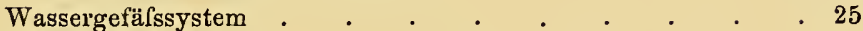

Rüssel . . . . . . . . . . . 26

Nervensystem . . . . . . . . . . . 28

3. Darmkanal . . . . . . . . . . 32

4. Zur Pathologie von M. Ehrenbergii . . . . 32

5. Entwicklungsgeschichte . . . . . . 33

Arten der Eier und Begattung . . . . . . . 33

Dotter und Dotterstöcke . . . . . . . . . 41

Furchungsprocefs . . . . . . . . . 45

Eibildung . . . . . . . . . . . . 48

Saamenbildung . . . . . . . . . . . 48

6. System der Plathelminthen und Nemathelminthen 50

Allgemeine Grundsätze . • . . . . . 50

System der Plathelminthen . . . . . . . 55

System der Nemathelminthen . . . . . . . . 58

7. Beschreibung einiger seltner Species . . . 61

1. Prorhynchus stagnalis $. \quad . \quad . \quad . \quad \cdot \quad \cdot \quad \cdot 61$

2. Mesostomum obtusum . $\quad$. $\quad$. $\quad . \quad$. 62

3. Stenostomum leucops . . . . . . . 62

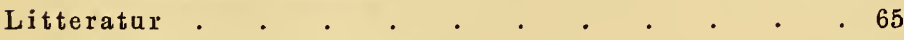

Erklärung der Abbildungen $\quad . \quad$. $\quad . \quad . \quad . \quad 67$ 


Druck von Wilhelm $\mathrm{Keller}$ in Giefsen. 


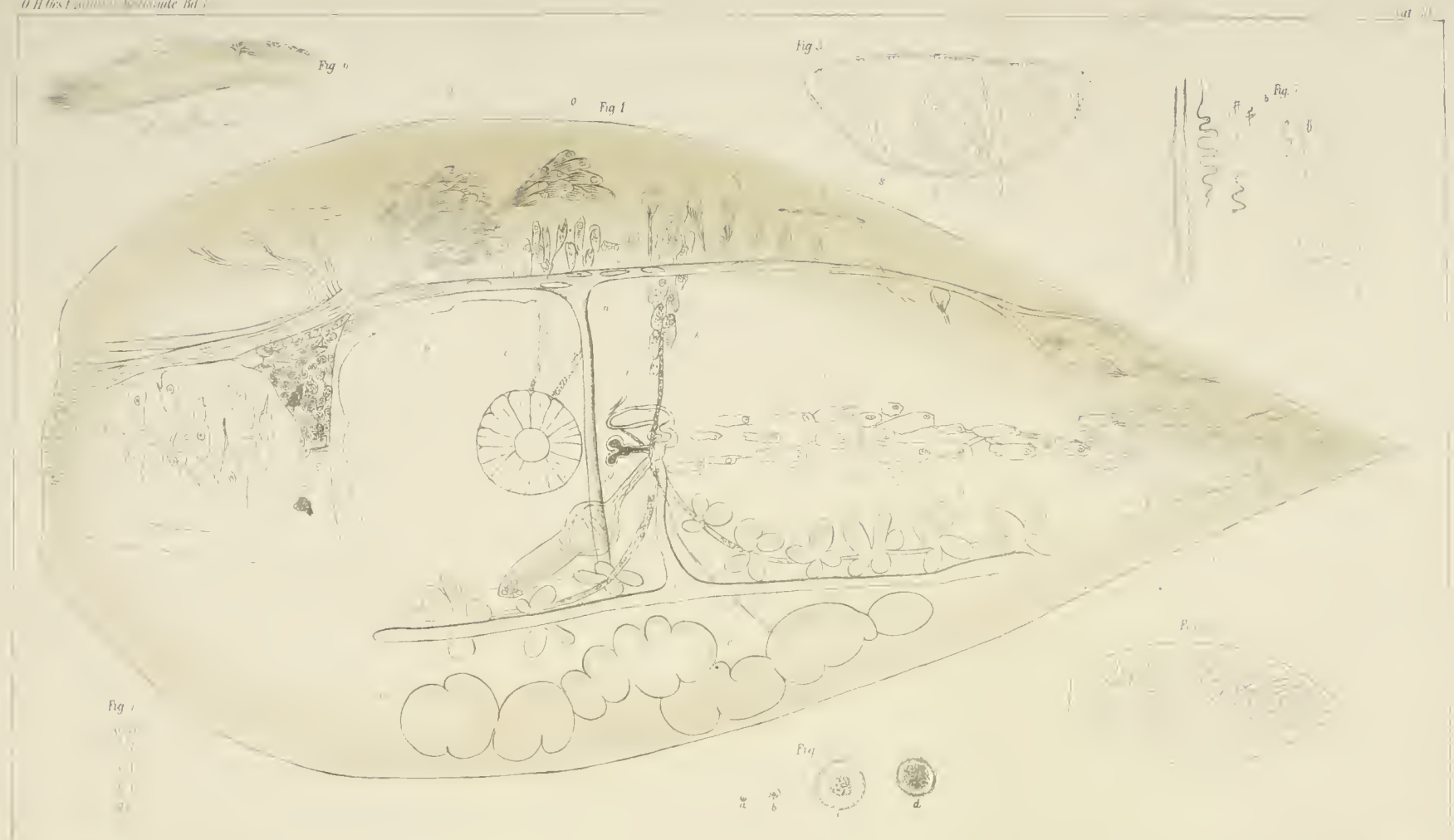





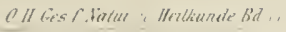

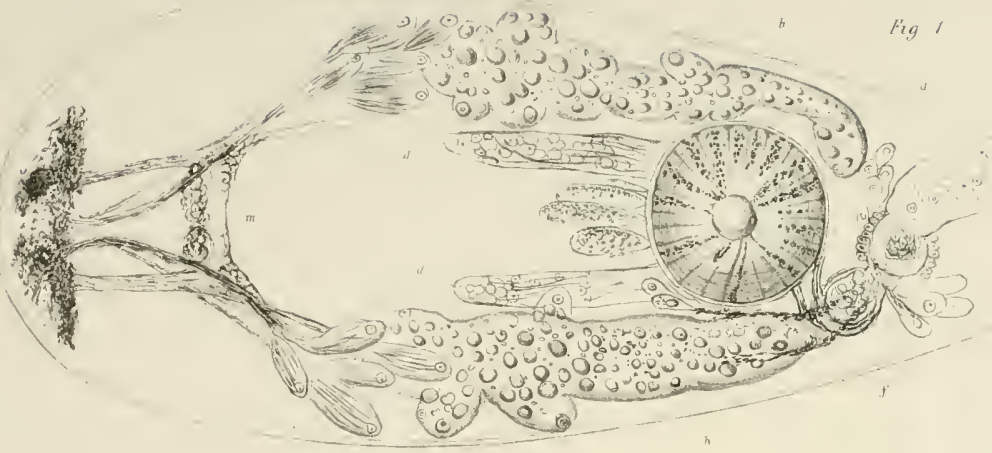

Fiy ? 



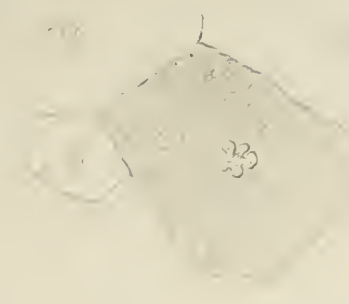

Fig 2."

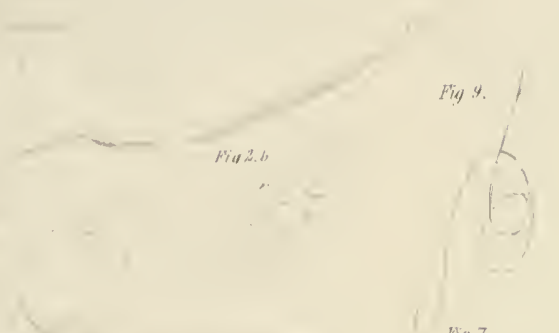

$\operatorname{lig} 7$

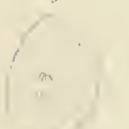

\section{Fiy ,i, a}

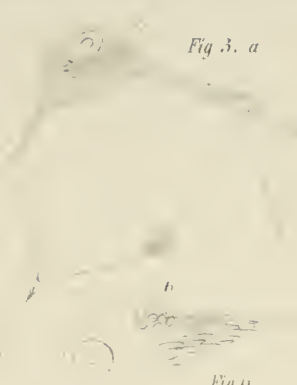

Fiy ")
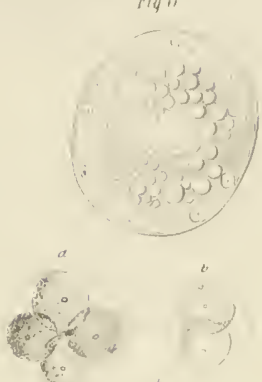

3)

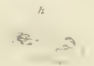

$\varepsilon=$

हल
Fig $w$.
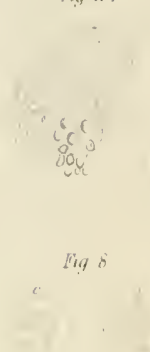

Mik. II

Fig 5

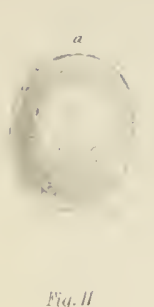

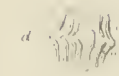

(1) ?

Witi

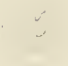

$\begin{aligned} & 1- \pm= \\ & \rightarrow=0\end{aligned} \mid$

$=$

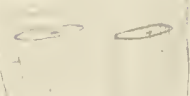

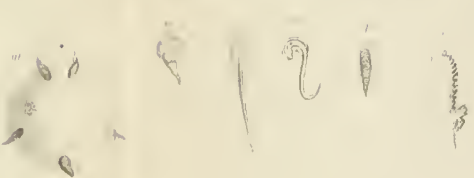





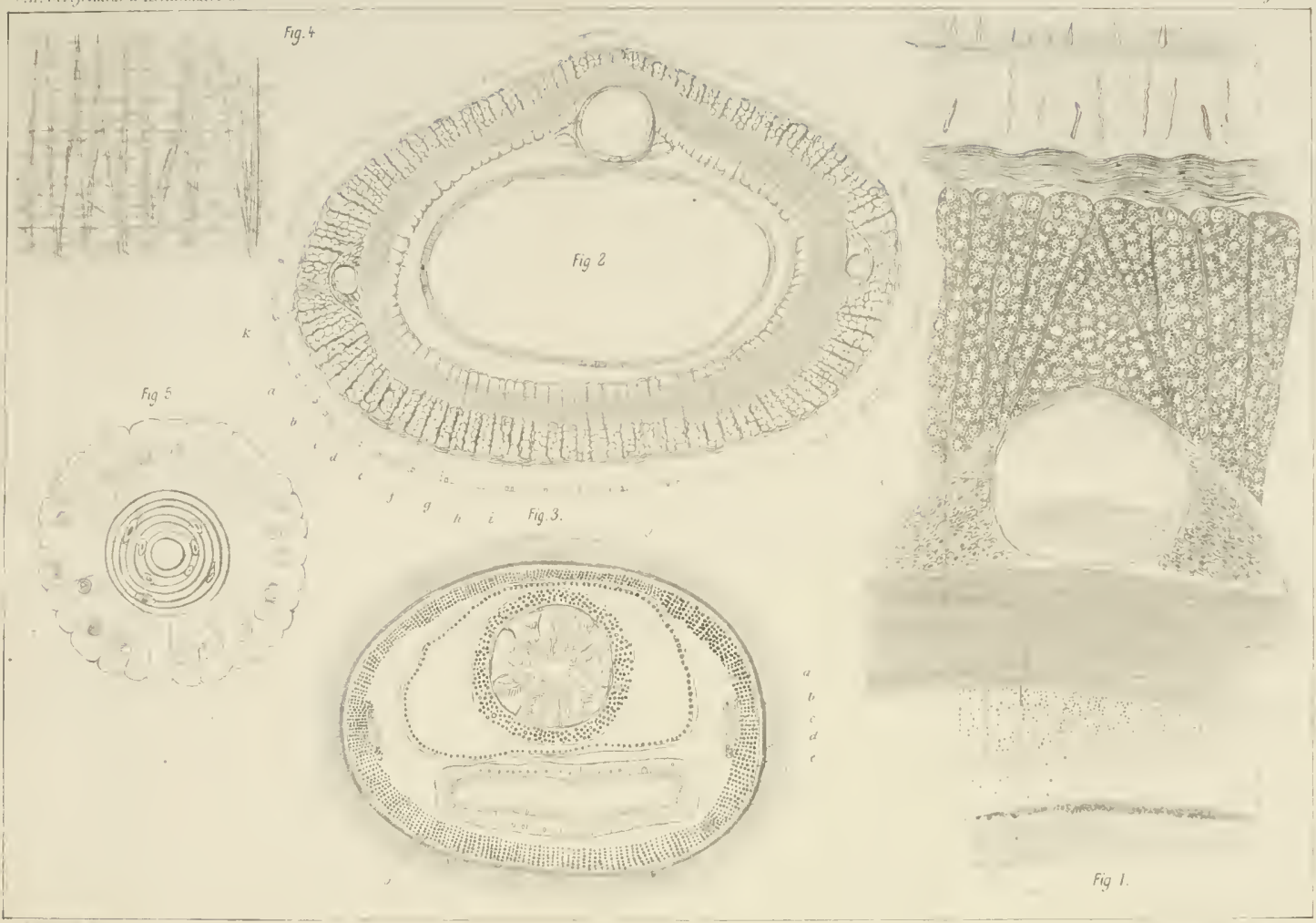





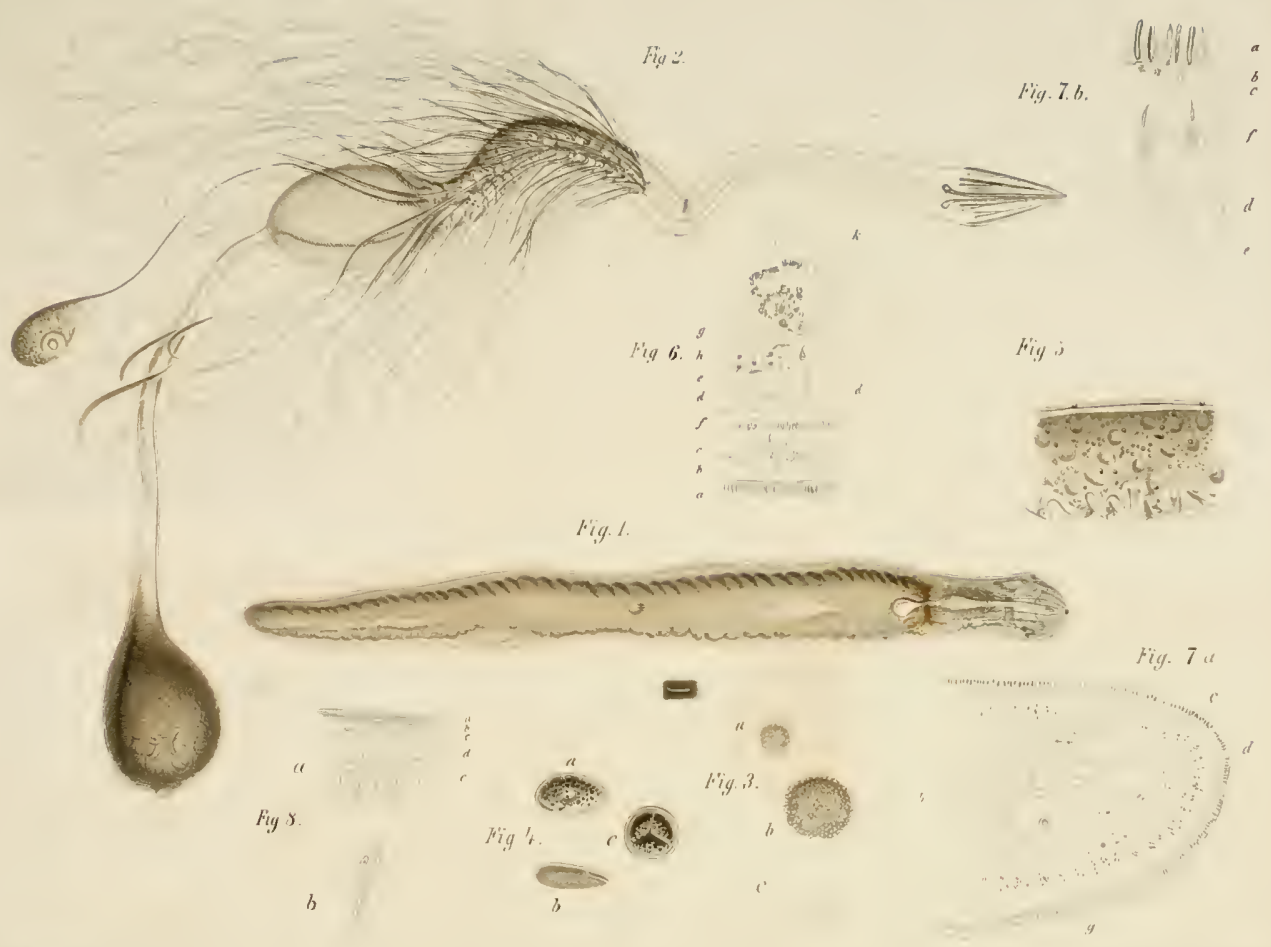







\section{$\cdot{ }^{\circ} N$}

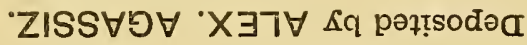

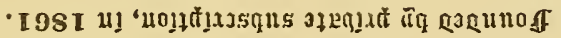

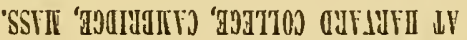

'XりOTỌOZ TLILVUVANOO

AO

นแบง

'zỊsse.ి 


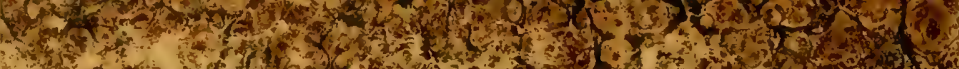

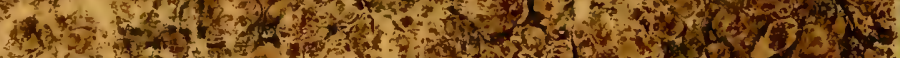

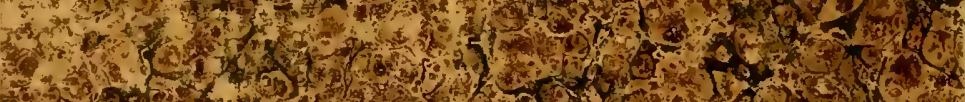

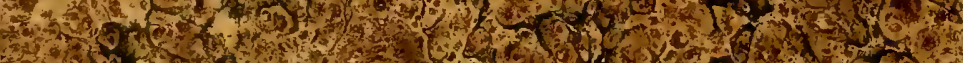

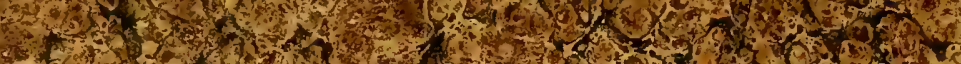

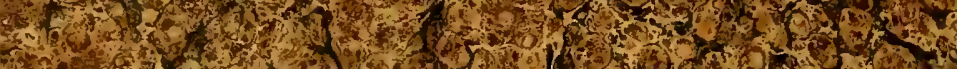

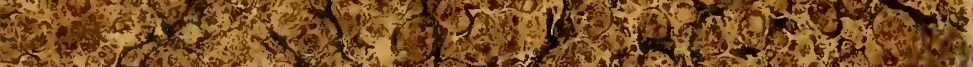

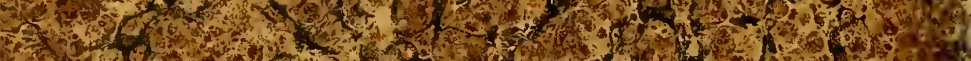

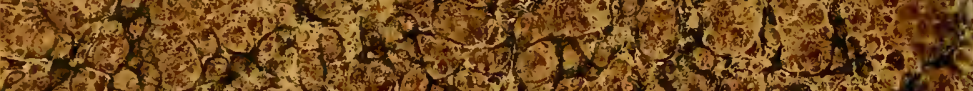

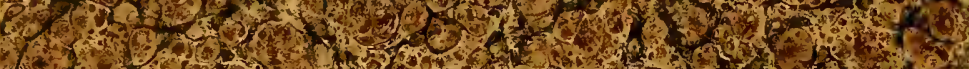

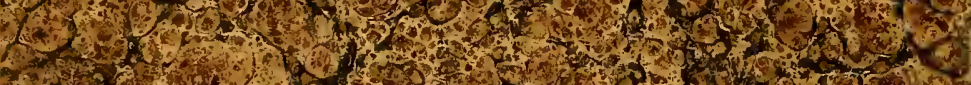

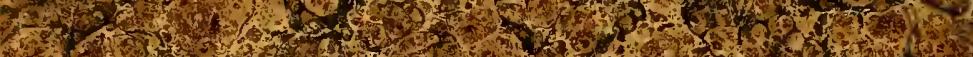
10
10

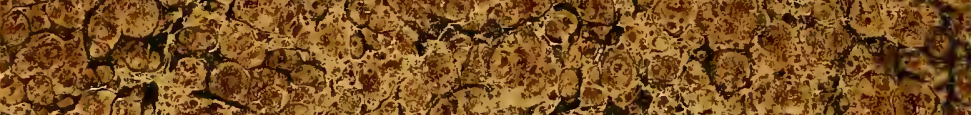

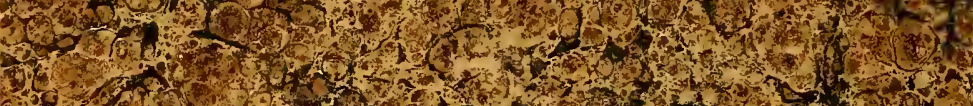

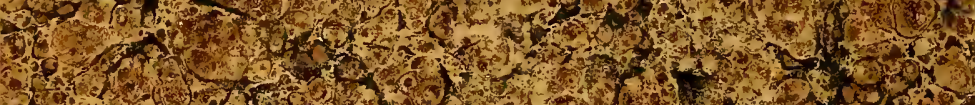

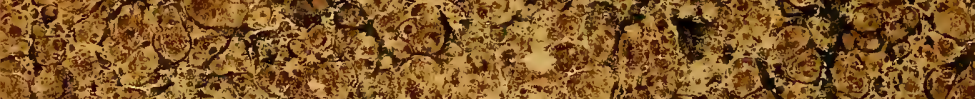

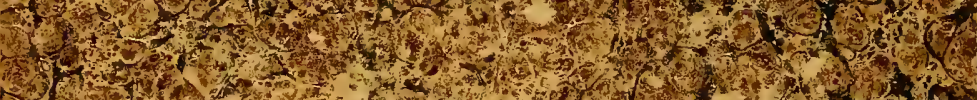

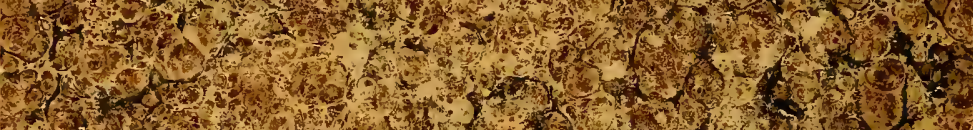

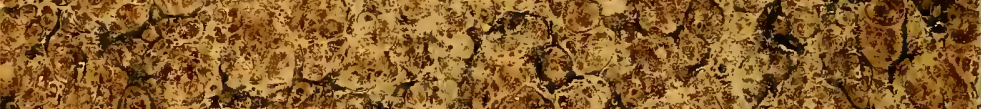

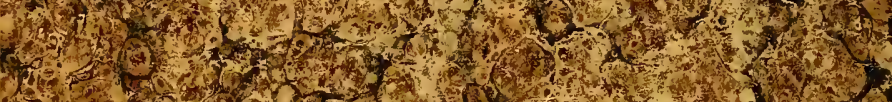
a

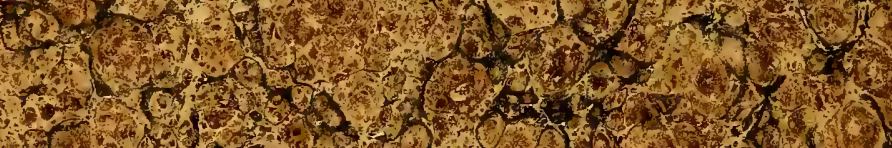

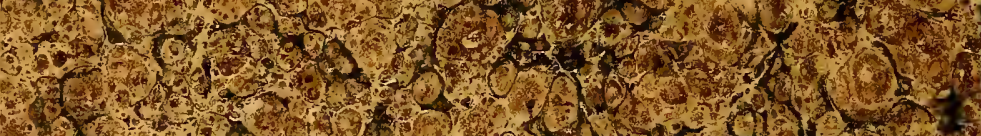
W.

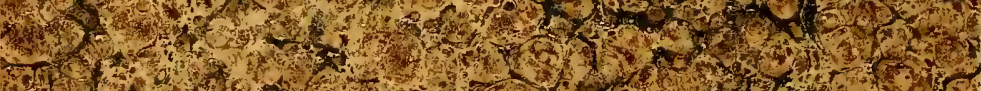

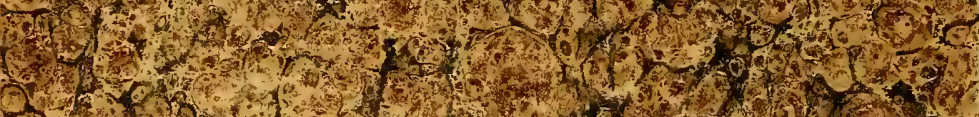
D.

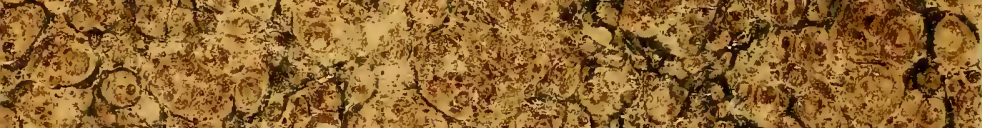

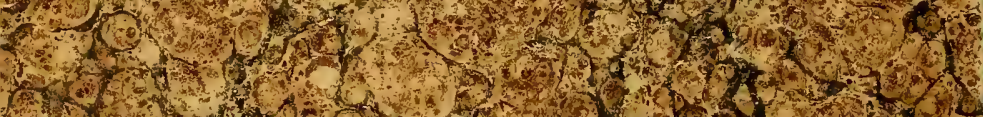

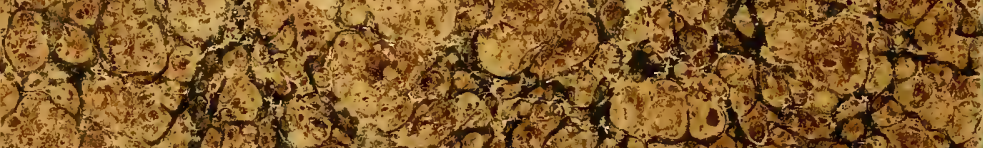
S. L. $2 x^{1}-1$

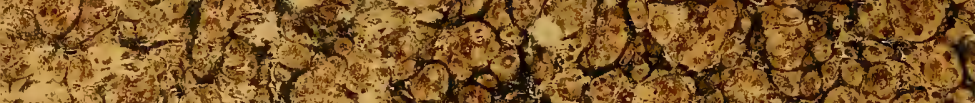

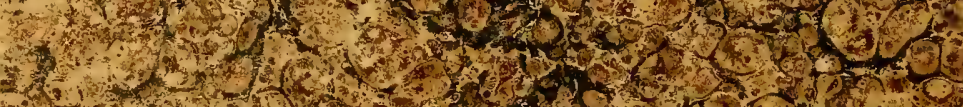

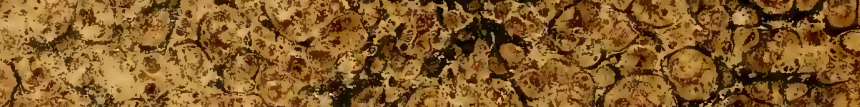

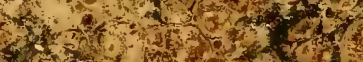

